\title{
RNA-Sequencing of Cercospora beticola DMI-sensitive and - resistant isolates after treatment with tetraconazole identifies common and contrasting pathway induction
}

\author{
Melvin D. Bolton ${ }^{\mathrm{a}, \mathrm{b}}$, Malaika K. Ebert ${ }^{\mathrm{a}, \mathrm{b}, \mathrm{c}, 1}$, Luigi Faino ${ }^{\mathrm{c}, 1}$, Viviana Rivera-Varas ${ }^{\mathrm{b}}$, Ronnie de \\ Jonge ${ }^{\text {d,e }}$, Yves Van de Peer ${ }^{\text {d,e }}$, Bart P. H. J. Thomma ${ }^{c}$, and Gary A. Secor ${ }^{\text {b }}$ \\ ${ }^{a}$ USDA - ARS, Northern Crop Science Laboratory, Fargo, ND, USA \\ ${ }^{\mathrm{b}}$ North Dakota State University, Department of Plant Pathology, Fargo, ND, USA \\ ${ }^{\mathrm{c}}$ Wageningen University, Laboratory of Phytopathology, Wageningen, The Netherlands \\ ${ }^{\mathrm{d}}$ Department of Plant Systems Biology, VIB, Ghent, Belgium \\ e Department of Plant Biotechnology and Bioinformatics, Ghent University, Ghent Belgium
}

Correspondence: Email: Melvin.Bolton@ars.usda.gov

${ }^{1}$ The contribution of these authors should be considered equal. 


\section{ABSTRACT}

Cercospora beticola causes Cercospora leaf spot of sugar beet. Cercospora leaf spot management measures often include application of the sterol demethylation inhibitor (DMI) class of fungicides. The reliance on DMIs and the consequent selection pressures imposed by their widespread use has led to the emergence of resistance in C. beticola populations. Insight into the molecular basis of tetraconazole resistance may lead to molecular tools to identify DMI-resistant strains for fungicide resistance management programs. Previous work has shown that expression of the gene encoding the DMI target enzyme (CYP51) is generally higher and inducible in DMI-resistant C. beticola field strains. In this study, we extended the molecular basis of DMI resistance in this pathosystem by profiling the transcriptional response of two $C$. beticola strains contrasting for resistance to tetraconazole. A majority of the genes in the ergosterol biosynthesis pathway were induced to similar levels in both strains with the exception of CbCyp51, which was induced several-fold higher in the DMI-resistant strain. In contrast, a secondary metabolite gene cluster was induced in the resistance strain, but repressed in the sensitive strain. Genes encoding proteins with various cell membrane fortification processes were induced in the resistance strain. Site-directed and ectopic mutants of candidate DMI-resistance genes all resulted in significantly higher $\mathrm{EC}_{50}$ values than the wild-type strain, suggesting that the cell wall and/or membrane modified as a result of the transformation process increased resistance to tetraconazole. Taken together, this study identifies important cell membrane components and provides insight into the molecular events underlying DMI resistance in C. beticola.

Keywords: ergosterol, sterol demethylation inhibitor, RTA1, cell-membrane, transformation, $\mathrm{EC}_{50}$, tetraconazole 


\section{INTRODUCTION}

Cercospora beticola causes Cercospora leaf spot (CLS) of sugar beet (Beta vulgaris). The fungus is considered to be the most destructive foliar pathogen of sugar beet worldwide. CLS is of significant concern to the $\$ 3$ billion United States sugar beet industry, which is the primary provider of refined sucrose used for natural sweetening domestically and has a growing interest to use sugar beet for biofuel production (Panella, 2010). Yield and quality losses from CLS together with costs associated with fungicide application result in annual losses in excess of several million dollars in the United States alone. The disease causes a reduction in root harvest weight and extractable sucrose due to loss of photosynthetic capacity and diversion of photosynthate from roots for foliage regeneration (Franc, 2010). Individual leaf spots are most commonly found on older leaves initially, but all leaves in advanced stages of disease may have numerous 3-5 mm circular leaf spot lesions harboring fungal stroma (Franc, 2010). Infection is initiated when sporulation from over-wintered stromata results in conidia being delivered to sugar beet leaf surfaces primarily by wind and water splash (Khan et al., 2008). After spore germination, the non-symptomatic biotrophic stage of disease development occurs when the fungus penetrates stomata to reach the apoplast where effectors released by invading hyphae facilitate infection (Daub and Ehrenshaft, 2000; Steinkamp et al., 1979). As early as five days after initial infection, the necrotrophic stage ensues and conidia produced in the resulting necrotic tissue can initiate another disease cycle provided environmental conditions are conducive (Franc, 2010). Although no sexual stage of $C$. beticola has been identified to our knowledge, population studies have shown that C. beticola populations carry the hallmarks of sexual reproduction (Bolton et al., 2014; Bolton et al., 2012c). Besides sugar beet, several hosts for C. beticola have been described (Lartey et al., 2005). Although the biological importance of these hosts is not clear, we cannot exclude the possibility that a sexual cycle occurs on hosts besides sugarbeet. Disease management measures for CLS include the use 
of tolerant sugar beet varieties and crop rotation, but the disease is managed effectively only when combined with timely fungicide applications (Khan et al., 2007; Secor et al., 2010).

A CLS outbreak occurred in 1998 that led to estimated losses of $\$ 45$ million in north central U.S. due to reduced yield and fungicide application costs (Secor et al., 2010). The subsequent year, the U.S. Environmental Protection Agency granted an emergency exemption for growers to use the nonregistered triazole fungicide tetraconazole, the first use of an azole to manage CLS, to help contain another CLS outbreak. Since then, tetraconazole and other triazoles have been popular because of protective and curative properties, and low levels of phytotoxicity. Reliance on triazole chemistries for CLS management has become even more pronounced with recent development of resistance to other chemistries including benzimidazole (Weiland and Halloin, 2001) and quinone outside inhibitors (Birla et al., 2012; Bolton et al., 2013a; Bolton et al., 2013b). The reliance on triazoles and the consequent selection pressures imposed by their widespread use has led to a shift in sensitivity in C. beticola populations (Bolton et al., 2012b; Secor et al., 2010).

Triazoles are the largest group of fungicides of the sterol demethylation inhibitors (DMIs) and act through inhibition of cytochrome P450-dependent sterol 14 $\alpha$-demethylase (CYP51), an enzyme required for biosynthesis of the fungal cell membrane component ergosterol (Cools et al., 2013). Resistance to DMIs is known to occur through a variety of mechanisms including amino acid exchanges in CYP51 (Carter et al., 2014; Cools et al., 2010; Leroux et al., 2007), elevated expression of Cyp51 (Cools et al., 2012; Ma and Tredway, 2013), and/or active efflux of fungicide from the cell due to increased expression of genes encoding membrane ATP-binding cassette $(A B C)$ and/or major facilitator superfamily transporters (Kretschmer et al., 2009; Zwiers et al., 2002). Recently, melanization has also been shown to play a role in DMI resistance (Lendenmann et al., 2015). DMI resistance in C. beticola is associated with over-expression of CbCyp51 (Bolton et al., 2012a). Although mutations in Cyp51 
regulatory elements have been shown to drive Cyp51 over-expression in other pathosystems (Carter et al., 2014; Ma et al., 2006), no similar promoter mutation could be identified in C. beticola (Bolton et al., 2012a). Since a mutation in Cyp51 regulatory elements is generally associated with constitutive overexpression (Cools et al., 2012; Hamamoto et al., 2000; Ma et al., 2006; Sun et al., 2013), the lack of a similar mutation in CbCyp51 may explain why CbCyp51 is inducible in DMI-resistant strains with expression levels that correlate with tetraconazole rates used in in vitro assays (Bolton et al., 2012a). The mechanism responsible for CbCyp51 inducible expression is not known.

In this study, we used RNA-seq technology to profile the transcriptional response of a C. beticola DMI-resistant and -sensitive strains to tetraconazole and acetone (control) treatments. Pathway analysis showed that flux through the ergosterol biosynthesis pathway is a response shared by both strains after exposure to tetraconazole. A majority of the genes in the ergosterol biosynthesis pathway were induced to similar levels in both strains with the exception of $C b C y p 51$, which was induced severalfold higher in the DMI-resistant strain. Surprisingly, site-directed and ectopic mutants of candidate DMIresistance genes all resulted in significantly higher $\mathrm{EC}_{50}$ values than the wild-type strain, suggesting that the transformation process increased resistance to tetraconazole. The implications of these genes for DMI resistance in the $C$. beticola pathosystem are discussed. 


\section{Materials and methods}

\subsection{Fungal strains and culture conditions}

Sugar beet leaves with Cercospora leaf spot were collected from commercial fields of the Red River Valley region of MN and ND. Conidia were harvested by adding $50 \mu \mathrm{L}$ of T-water $(0.06 \%(\mathrm{v} / \mathrm{v})$ Tween 20 (Sigma-Aldrich, St. Louis, USA), 0.02\% (w/v) filter-sterilized ampicillin added after the solution had been autoclaved) to the surface of a C. beticola leaf spot lesion. The lesion was gently scraped with a pipette tip to liberate conidia into the T-water. The conidia-laden T-water was collected and transferred to water agar plates (1.5\% (w/v) agar (BD, Franklin Lakes, USA), $0.02 \%(\mathrm{w} / \mathrm{v})$ filter-sterilized ampicillin added after the solution had been autoclaved) for $24 \mathrm{~h}$ at $22^{\circ} \mathrm{C}\left( \pm 1^{\circ} \mathrm{C}\right)$ to initiate conidia germination. One germinated conidium was transferred to a clarified V8-medium plate (10\% (v/v) clarified V8 juice (Campbell's Soup Co., Camden, USA), 0.5\% (w/v) $\mathrm{CaCO}_{3}$, and 1.5\% (w/v) agar (BD)) and was incubated at $25^{\circ} \mathrm{C}$ for two weeks. This single spore-derived colony was the source inoculum plate for subsequent fungicide sensitivity assays.

$\mathrm{EC}_{50}$ calculations were carried out as described by Secor and Rivera (2012). Briefly, agar plugs (5 $\mathrm{mm}$ each) were taken from the leading edge of colony growth of the original non-amended V8-agar plates described above and placed on V8-agar plates amended with serial ten-fold dilutions of active ingredient from 0.001 to $1.0 \mathrm{\mu g} \mathrm{ml}^{-1}$. After 15 days, inhibition of radial growth was measured and compared to growth on non-amended medium and was used to calculate an $\mathrm{EC}_{50}$ value for each isolate. Cercospora beticola strains 09-32 (DMI-sensitive) and 10-73-4 (DMI-resistant) were used in this study based on $\mathrm{EC}_{50}$ value determination.

Liquid cultures of 09-32 and 10-73-4 were initiated by placing an agar plug taken from the leading edge of the clarified V8-medium plates (described above) into a $250 \mathrm{~mL}$ flask containing $50 \mathrm{~mL}$ potato dextrose broth (BD). Each isolate was allowed to grow for $96 \mathrm{~h}$ after which $5 \mu \mathrm{L}$ of tetraconazole stock 
solution (10 $\mathrm{g} \mathrm{mL}^{-1}$ in acetone) was added to each flask for a final concentration of $1.0 \mu \mathrm{g} \mathrm{mL}^{-1}$ as described by Bolton et al. (2012a). As a control, each isolate was also grown as described above except $5 \mu \mathrm{L}$ acetone was added in place of tetraconazole. Flasks were shaken $(125 \mathrm{rpm})$ for $48 \mathrm{~h}$ at $22^{\circ} \mathrm{C}\left( \pm 1^{\circ} \mathrm{C}\right)$ after which mycelium was harvested using a Büchner funnel and immediately frozen in liquid nitrogen. Total RNA was isolated from mycelium using the RNeasy Plant Mini kit (Qiagen; Venlo; Netherlands) following the manufacturer's instructions that included an on-column DNAse treatment (Qiagen). There was two flasks of each fungal strain/treatment for each of two biological replicates.

\subsection{Genome assembly and gene prediction}

Two sequence libraries (500-bp and 5-kb insert size) of Cercospora beticola strain 10-73-4 were prepared and sequenced at the BGI Americas (Cambridge, USA) using the Illumina high throughputsequencing platform. Genome assembly was performed using A5 pipeline (default settings) (Tritt et al., 2012). Gene prediction was performed by aligning sequences from the predicted transcriptome of the DMI-sensitive $C$. beticola strain 09-40 (de Jonge and Bolton, unpublished data) to the genome of $C$. beticola 10-73-4 by GMAP software (settings: -fulllength ; -format=gff3_gene) (Wu and Nacu, 2010).

\subsection{Expression analysis}

Two biological replicates for each treatment were used for RNA-seq analysis. RNA-seq libraries (180 bp insert size) were prepared and sequenced (100- bp reads) by BGI Americas. RNA-seq data were aligned to the genome of $C$. beticola strain 10-73-4 using STAR (v2.5) software (Dobin et al., 2013) using the following options: --alignIntronMax 1000 --alignMatesGapMax 1000 --outFilterMismatchNmax 15 -outSAMstrandField intronMotif --outFilterIntronMotifs RemoveNoncanonical --outSAMattrlHstart 1. Cuffdiff, within the Cufflinks (v2.2.1) software package (Roberts et al., 2011), was used to estimate transcript level changes of the replicate experiments. The dataset for this project can be obtained at http://www.ncbi.nlm.nih.gov/bioproject/294383. 


\subsection{Transformation and disruption of target genes}

Split-marker PCR constructs for targeted gene replacement were prepared as described by Catlett et al. (2003) using genomic DNA of 10-73-4 wild type C. beticola and pDAN (Friesen et al., 2006) as PCR templates. Primers for split-marker development are listed in Table 4.

A $5 \mathrm{~mm}$ plug was taken from the actively growing zone of $C$. beticola wild type strain 10-73-4 on potato dextrose agar (PDA; BD). Liquid cultures were initiated by grinding the plug with $500 \mu \mathrm{L}$ Fries media (Friesen and Faris, 2012), which was subsequently transferred to a $125 \mathrm{~mL}$ flask containing $50 \mathrm{ml}$ Fries media. Flasks were wrapped in aluminum foil and shaken at $150 \mathrm{rpm}$ at $21^{\circ} \mathrm{C}$ for four days. Cultures were then transferred to a sterile blender cup, ground for $10 \mathrm{~s}$, and transferred to a $500 \mathrm{~mL}$ flask containing $200 \mathrm{~mL}$ Fries media. Cultures were grown as described above for an additional 24 hours after which mycelium was harvested with two layers of Miracloth (Calbiochem, Billerica, USA) using a Büchner funnel. The mycelium was rinsed with mycelium wash solution $\left(0.7 \mathrm{M} \mathrm{KCl}, 10 \mathrm{mM} \mathrm{CaCl} 2 \cdot 2 \mathrm{H}_{2} \mathrm{O}\right)$, broken into small pieces with a sterile spatula, transferred to deep petri dish containing $40 \mathrm{~mL}$ of osmoticum (20 g L${ }^{-1}$ lysing enzymes from T. harzianum (Sigma-Aldrich) and $12.5 \mathrm{~g} \mathrm{~L}^{-1}$ Driselase (SigmaAldrich), and incubated at $30^{\circ} \mathrm{C}$ for 6 to $8 \mathrm{~h}$ while shaking at $50 \mathrm{rpm}$. Protoplasts were harvested by filtering the osmoticum solution through two layers of Miracloth and collected by centrifugation ( $2000 \mathrm{x}$ $g$ for $5 \mathrm{~min}$ ). After a washing step with $15 \mathrm{~mL} \mathrm{STC} \mathrm{(1} \mathrm{M} \mathrm{Sorbitol,} 10 \mathrm{mM}$ Tris- $\mathrm{HCl} \mathrm{pH}$ 7.5, $10 \mathrm{mM} \mathrm{CaCl}_{2}$ ), protoplasts were adjusted to $10^{8} \mathrm{~mL}^{-1}$ with STC:PEG (4:1) and divided into $200-\mu \mathrm{L}$ aliquots. Subsequently, PEG-based transformation was performed essentially as described by Liu and Friesen (2012) using $70 \mu \mathrm{g}$ of each construct per $200 \mu \mathrm{L}$ protoplast aliquot. As a regeneration step, protoplasts were mixed with 10 $\mathrm{mL}$ of regeneration medium agar, poured into a petri dish, and kept in the dark at $21^{\circ} \mathrm{C}$. After $14 \mathrm{~h}$, the plate was overlaid with $10 \mathrm{~mL}$ regeneration medium agar containing $150 \mu \mathrm{g} \mathrm{mL}^{-1}$ Hygromycin B (Roche Diagnostics, Indianapolis, USA) for transformant selection. After 10 days, putative transformants were transferred to PDA plates amended with $150 \mu \mathrm{gLL}^{-1}$ hygromycin. 
DNA was extracted from PDA cultures using a modified version of the microprep protocol published by Fulton et al. (1995), replacing chloroform:isoamyl (24:1) with phenol:chloroform:isopropanol (25:24:1). PCR amplifications were carried out using the GoTaq Flexi DNA Polymerase kit (Promega, Madison, WI) following the manufacturer's suggested protocol. Site-directed transformation was confirmed by the presence of PCR products generated with a forward primer designed to anneal upstream of the $5^{\prime}$ flanking region of each individual target gene $(5 \mathrm{~F})$ and a reverse primer annealing to the 5' end of the hygromycin resistance encoding gene (HYG R2) (Table 4). Additionally, knock-out mutants were verified by the absence of a PCR product when using forward primer (1F) of the target gene $5^{\prime}$ flank and a reverse primer designed on the target gene coding sequence (6R) (Table 4). The presence of a 1F/6R PCR product and absence of a 5F/HYG R2 PCR product indicated a mutant with an ectopic integration of the construct. Verified isolates were stored at $22^{\circ} \mathrm{C}$ in the dark until used for fungicide sensitivity assays, which were carried out within three weeks of verification. 


\section{RESULTS}

\subsection{Cercospora beticola transcript level changes after exposure to tetraconazole}

Two isolates harvested from the north central U.S. sugar beet growing area contrasting for DMI sensitivity were used in this study. Cercospora beticola strain 09-32 is sensitive to all DMIs used for CLS management exhibiting an $\mathrm{EC}_{50}$ of $0.006 \mathrm{~g} \mathrm{ml}^{-1}$ to tetraconazole while DMI-resistant strain 10-73-4 has an $\mathrm{EC}_{50}$ to tetraconazole of $35.9 \mu \mathrm{g} \mathrm{ml}^{-1}$. The genome sequence of $C$. beticola strain 10-73-4 was determined using sequencing-by-synthesis on the Illumina HiSeq-2000, which served as the reference sequence in this study. To this end, $\sim 1.5 \mathrm{~Gb}$ of paired-end (PE) library-derived reads (500-bp insert size; 100-bp read length) was produced in combination with $\sim 1.5 \mathrm{~Gb}$ of mate-pair (MP) library-derived reads (5-kb insert size; 100-bp read length). The PE and MP sequences were assembled using the A5 pipeline (Tritt et al., 2012) and 105 scaffolds were generated with an N50 of about $405 \mathrm{~kb}$ and the longest contig of $2,475 \mathrm{~kb}$. The assembled genome was used for gene annotation. In total, 12,440 genes were predicted on the $C$. beticola strain 10-73-4 strain using the coding sequences from the manual gene annotation of C. beticola strain 09-40 (de Jonge and Bolton, unpublished data). Both 09-32 and 09-40 are $98.3 \%$ identical on the nucleotide level to $10-73-4$. An average of $98.0 \%$ and $99.4 \%$ of reads were mapped to the reference sequence across replicates and treatments for 09-32 and 10-73-4, respectively

(Supplemental Table 1). Out of 12,440 genes, about 11,587 have RNA-seq support for more than $95 \%$ of the gene length.

Both isolates were grown in vitro followed by a tetraconazole or acetone treatment as described by Bolton et al. (2012a). Although any pair-wise comparison could be made between isolates and treatments, we sought to identify transcript level changes solely associated with the response to tetraconazole in each strain. Since $C$. beticola isolates are typically genetically diverse (Bolton et al., 2012c), comparisons within a single genetic background negate any between-genotype background 
variation that may inadvertently identify genes not associated with tetraconazole resistance. Therefore, we employed a univariate analysis ( $t$ tests, $Q$-value $\leq 0.001$, and $\log _{2}$ fold regulation differences $\geq 1.0$ ) between mock- and tetraconazole-treatments for each $C$. beticola strain.

We identified 414 genes that were differentially-expressed between mock- and-tetraconazoletreatments in the DMI-sensitive isolate 09-32 (Fig. 1). Of the 286 genes uniquely identified in 09-32, 115 were induced and 171 were repressed (Supplemental Table 2). To characterize the biological processes underlying these 286 genes, Of these genes, 213 were induced and 216 were repressed/Supplemental Table 2). To characterize the biological processes that occurred in the DAM-sensitive-strain in response to tetraconazole, we used gene ontology (GO) term enrichment analysis which revealed 11 and $21 \mathrm{GO}$ terms significantly over and under-represented, respectively (Supplemental Table 3). However, since previous work in our laboratory revealed that CbCyp51 was induced upon exposure to tetraconazole in DMI-resistant isolates (Bolton et al., 2012a), we were primarily interested in identifying genes with expression profiles similar to CbCyp51 that were differentially-expressed after exposure to tetraconazole in the DMI-resistant strain 10-73-4 when compared to the control treatment. To that end, we identified 244 genes differentially-expressed between mock- and tetraconazole-treatments in 10-73-4 (Fig. 1) of which 172 were induced and 72 repressed. In total, 128 genes were differentially-expressed in both isolates as a consequence of tetraconazole exposure (Fig. 1).

\subsection{Classification of genes differentially-expressed in both strains in response to tetraconazole}

Although we were primarily interested in identifying genes induced in response to tetraconazole in the DMI-resistant isolate, identifying pathways induced in both strains as a consequence of tetraconazole exposure may characterize the background and perhaps a more universal response to tetraconazole in this pathosystem. We identified 128 genes differentially-expressed in both $C$. beticola strains (Fig. 1). These genes were analyzed with InterPro (Mitchell et al., 2014) and PFAM (Finn et al., 2014) to aid in protein functional analysis by classifying into protein families by predicting domains and 
other important sites. GO terms (Ashburner et al., 2000) were further applied to classify genes into specific processes to aid in pathway reconstruction (Table 1). GO term enrichment analysis revealed four GO terms significantly over-represented in both strains, which included lipid metabolic processes (GO:0006629), oxidoreductase activity (GO:0016491), catalytic activity (GO:0003824), and the cellular component endoplasmic reticulum (GO:0005783) (Supplemental Table 4). In contrast, cellular processes (GO:0009987), cellular metabolic processes (GO:0044237), and protein metabolic processes (GO:0019538) were repressed in both strains (Supplemental Table 4). In total, InterPro and PFAM classifications were available for 94 and 80 genes, respectively, which enabled the classification of nearly half of the identified genes into $27 \mathrm{GO}$ term categories (Table 1).

Four genes involved with the isoprenoid biosynthetic process (Table 1) were induced in both strains. Isoprenoids, also known as terpenoids, are a large class of ubiquitous metabolites synthesized through the condensation of $C_{5}$ units that are precursors for ergosterol biosynthesis in fungi. Further analysis of the gene list (Table 1 ) identified an additional gene (Erg10) in the terpenoid backbone biosynthesis pathway (KEGG Pathway map00900) involved in ergosterol production (Fig. 2A). The last gene in the terpenoid backbone biosynthesis pathway leading to steroid biosynthesis (KEGG Pathway map00100) is farnesyl diphosphate synthase (FDS), giving rise to farnesyl diphosphate, the initial substrate for the steroid biosynthesis pathway (Fig. 2A). In total, we identified 11 genes in the steroid biosynthesis pathway leading to the production of ergosterol that were induced in both strains (Fig. 2A). Additionally, the Erg26 gene that is involved with ergosterol production was only differentiallyexpressed in 10-73-4 (see below) but was also included in Figure 2. To compare the expression for each gene in both treatments for each isolate, we plotted FPKM reads for each gene identified as differentially-expressed (Fig. 2B). Although Cyp51 was shown to have a higher relative expression in the DMI-sensitive strain 09-32 (5.10 $\log _{2}$ fold change) compared to the DMI-resistant strain $\left(3.57 \log _{2}\right.$ fold change) (Table 1), analysis of the FPKM values illustrate that Cyp51 was induced to a much higher level 
in DMI-resistant strain 10-73-4 after tetraconazole exposure (Fig. 2B). To confirm that differential Cyp51 expression was not due sequence polymorphism between strains, we confirmed that the coverage of RNA-seq reads was uniform for 09-32 and 10-73-4 along the Cyp51 coding region (Supplementary Fig. 1). Similarly, expression of Erg3 was much higher in 10-73-4 than 09-32 after tetraconazole exposure (Fig. 2B). However, most genes had similar FPKM values between the two strains for each treatment (Fig. 2B). In total, 17 of the 23 genes in the ergosterol biosynthesis pathway were induced in both strains upon tetraconazole exposure (Fig. 2), suggesting ergosterol biosynthesis is a universal response to tetraconazole in C. beticola. In support of this hypothesis, two key regulators of sterol homeostasis, sterol regulatory element-binding protein ortholog Sre1 and sterol regulatory element-binding protein cleavage-activating protein, were induced in both strains after tetraconazole treatment (Table 1). In addition, a gene with a CRAL/TRIO and Sec14p-like domain was induced in both strains (Table 1). Proteins with these domains are known to be involved with lipid binding (Panagabko et al., 2003) and have been associated with resistance to DMIs in yeast (Šimová et al., 2013).

Polyketide synthases (PKSs) catalyze the elongation of polyketides and are among the most prominent and well-studied fungal secondary metabolite biosynthetic genes. Genes involved with the modification of intermediate products formed from such enzymes are typically found in a contiguous gene cluster that may also include a transport-related gene involved with SM efflux and/or a pathwayspecific transcription factor that control expression of the cluster (Thomma et al., 2015). A polyketide biosynthesis gene cluster (CBET3_11350-RA to CBET3_11356; Table 1) was differentially-expressed in response to tetraconazole between the two isolates. CBET3_11350-RA is a predicted non-reducing polyketide synthase (de Jonge and Bolton, unpublished) and together with five other genes in the cluster was induced in the tetraconazole-resistant strain 10-73-4 but were all repressed in the sensitive strain 09-32 (Table 1). Additionally, genes encoding a PKS (CBET3 09638-RA) and a tetrahydroxynaphthalene reductase (CBET3 09636-RA) that belong to the same PKS cluster (de Jonge and Bolton, unpublished), 
were induced in the resistant strain but repressed in the sensitive strain (Table 1). CBET3 009636 is an ortholog to PKS1 from Zymoseptoria tritici, which was recently shown to be associated with increased melanization and DMI-resistance (Lendenmann et al., 2015).

\subsection{Classification of genes differentially-expressed in DMI-resistant strain in response to tetraconazole}

InterPro and PFAM classification was available for 86 and 77 genes, respectively, permitting the classification of nearly half of the differentially-expressed genes identified in the DMI-resistant strain into $21 \mathrm{GO}$ term categories (Table 2). No obvious pathways unique to 10-73-4 were up-regulated in response to tetraconazole. GO term enrichment analysis revealed a single GO term (secondary metabolic process; GO:0019748) over-represented (Supplemental Table 5). Several genes involved directly or indirectly with the fungal cell membrane or cell wall were induced in response to tetraconazole. For example, a gene containing an RTA1 domain known to encode a plasma membrane protein (Manente and Ghislain, 2009) was the most highly differentially-expressed gene in the study (Table 2). RTA1 encodes a protein with seven potential transmembrane domains and has been shown to mediate resistance to 7-aminocholesterol, a class of sterol biosynthesis inhibitors (Soustre et al., 1996). Another gene belonging to the Gpr1/Fun34/YaaH family encoding a plasma membrane protein was induced in 10-73-4 (Table 2). Although there is no sequence conservation with RTA1, this protein is also an integral protein of the plasma membrane with six transmembrane domains as has been shown in the yeast Yarrowia lipolytica (Augstein et al., 2003). Additionally and as mentioned above, Erg26, which is in the ergosterol pathway, was specifically induced in 10-73-4 (Table 2).

Several genes encoding proteins involved with transmembrane transport were differentiallyexpressed in 10-73-4. Of particular interest are major facilitator superfamily (MFS) and ATP-binding cassette $(A B C)$ transporters, which have been shown to be associated with fungicide resistance by active efflux of xenobiotics (Cools et al., 2013; Roohparvar et al., 2008; Zwiers et al., 2002). We identified five 
MFS and two ABC transporters induced in 10-73-4 in response to tetraconazole (Table 2). Several genes with a more indirect putative role in the fungal cell wall were also implicated in fungicide resistance in $C$. beticola strain 10-73-4. For example, numerous genes encoding glycoside hydrolase family proteins were differentially-expressed in 10-73-4 (Table 2). Glycoside hydrolases are a widespread group of enzymes that hydrolyze the glycosidic bond between two or more carbohydrates or between a carbohydrate and a non-carbohydrate moiety, and are classified largely on substrate specificity but occasionally by mode of action. Seven genes encoding four glycoside hydrolase families were induced in response to tetraconazole in 10-73-4 (Table 2). Three glycoside hydrolase family 16 genes were induced, which are known to encode enzymes that break down $\beta$-1,3-glucans, a major component of fungal cell walls (Bowman and Free, 2006).

Since there is no CbCyp1 promoter regulatory polymorphism associated with enhanced DMI resistance (Bolton et al., 2012a) as has been shown in other fungal systems (Hamamoto et al., 2000; Ma et al., 2006; Schnabel and Jones, 2001), we are interested in identifying transcription factors responsible for CbCyp51 and other DMI-associated gene up-regulation. In this study, we identified one transcription factor uniquely induced in 10-73-4 (Table 2). This transcription factor is of the $\mathrm{Zn}(\mathrm{II})_{2} \mathrm{Cys}_{6}$ class and shares homology to Aspergillus spp. AfIR (Table 2). AfIR transcription factor orthologs are known to regulate biosynthesis of several secondary metabolites including aflatoxin, sterigmatocystin, and dothistromin (Bradshaw et al., 2013; Brown et al., 1996).

Five genes encoding cytochrome P450s (CYPs) were induced in 10-73-4 after tetraconazole treatment (Table 2). Fungal CYPs carry out a wide range of functions dependent on their enzymatic properties and substrate specificity in both primary and secondary metabolism (Lah et al., 2008). Similarly, other genes with a diversity of functions were induced including $\alpha / \beta$ hydrolases, carbohydrate esterases, and genes with FAD/NAD(P)-binding domains (Table 2). 


\subsection{Generation of mutants in candidate genes associated with DMI-resistance}

To aid in establishing a role in DMI-resistance, several genes were chosen for further characterization based on expression values and/or confirmed roles in DMI resistance in other pathosystems. Genes were characterized by replacing the gene of interest from the genome of DMI-resistant strain 10-73-4 with a gene encoding hygromycin $\mathrm{B}$ resistance, followed by analysis of $\mathrm{EC}_{50}$ values compared to the ectopic mutants of the same gene and the progenitor wild-type strain (Table 3). Average $\mathrm{EC}_{50}$ values were calculated based on individual $\mathrm{EC}_{50}$ values measured from three independent ectopic and sitedirected transformants. The average $\mathrm{EC}_{50}$ of three independent measurements of the wild-type progenitor strain 10-73-4 was $35.9 \mathrm{\mu g} \mathrm{ml}^{-1}$. Regardless of the gene chosen for replacement or whether the transformation event resulted in a site-directed or ectopic mutant, average $\mathrm{EC}_{50}$ values of all mutants was significantly higher than the progenitor wild-type strain (Table 3), suggesting that the transformation process alone increased resistance to tetraconazole. Transformations and subsequent $\mathrm{EC}_{50}$ evaluations were repeated, which provided similar results (not shown).

To investigate this phenomenon further, we produced protoplasts from two additional C. beticola strains and compared their $\mathrm{EC}_{50}$ values to their progenitor strains that did not go through the protoplast process. These experiments were identical to previous transformation procedures except no gene encoding a selection marker was included and therefore protoplasts were recovered from plates lacking hygromycin selection. Protoplasting caused a $25.7 \%$ and $6.4 \%$ increase in $\mathrm{EC}_{50}$ value, respectively, compared to the non-protoplasted progenitor strain. To investigate if the elevated $\mathrm{EC}_{50}$ values were transient in nature, we cycled mutant strains through two cycles of PDA growth, but observed similar levels of fungicide resistance (not shown).

\section{Discussion}


The fungal pathogen $C$. beticola is the most important foliar pathogen of sugar beet and requires well-timed fungicide applications for disease management. Due to widespread use of tetraconazole, resistance has been increasing in C. beticola populations in recent years (Bolton et al., 2012b; Secor et al., 2010). Insight into the molecular basis of tetraconazole resistance may lead to molecular tools to identify DMI-resistant strains for fungicide resistance management programs. In this study, we profiled the response of two $C$. beticola strains contrasting for resistance to the important DMI fungicide tetraconazole. Although our initial interest was to identify induced genes in the DMI-resistant strain, we observed a large overlap of genes differentially-expressed in both strains (Fig. 1) suggesting a common background response when exposed to tetraconazole. Notably, 17 of the 23 genes in the ergosterol biosynthesis pathway were induced in both strains upon tetraconazole exposure (Fig. 2). The clear induction of ergosterol pathway genes suggests maintenance or reinforcement of cell membrane integrity is a universal response when exposed to tetraconazole. Similarly, a strain of Aspergillus niger responded to the ergosterol-targeting fungicide fenpropimorph with enhanced expression of several ergosterol pathway genes identified using an Affymetrix microarray (Meyer et al., 2007). Cools et al. (2007) used a cDNA microarray approach to identify three induced genes in a epoxiconazole-sensitive

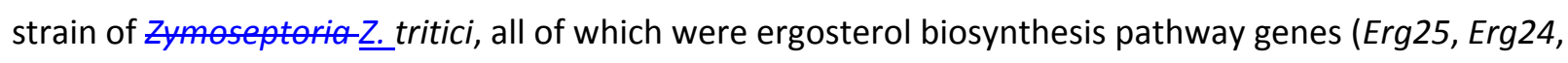
and Erg5). These same genes were induced in the $Z$. tritici epoxiconazole-resistant strain, but with lower transcript levels (Cools et al., 2007). In the human pathogen Candida albicans, induced expression of Cyp51 and other genes involved with ergosterol biosynthesis has been shown to be associated with DMI exposure (De Backer et al., 2001; Dunkel et al., 2008; Liu et al., 2005). Although most ergosterol biosynthesis genes were induced to similar levels in our study, CbCyp51 was induced to much higher levels in the DMI-resistant strain compared to the sensitive strain (Fig. 2), underlying a key difference between sensitive and resistant $C$. beticola strains and supporting our previous results that showed native $C b C y p 51$ expression is generally higher and expression is inducible in DMI-resistant field strains 
(Bolton et al., 2012a). Notably, the $C$. beticola HMGCR gene, which encodes the rate-controlling enzyme of the mevalonate pathway in terpenoid backbone biosynthesis leading to ergosterol production, was induced in both strains in response to tetraconazole (Table 1). The mechanism for the up-regulation of CbCyp51 or other ergosterol biosynthesis genes is currently not known in C. beticola. In the human pathogen Candida albicans, the zinc cluster transcription factor Upc2p has been shown to regulate the expression of Cyp51 and other genes involved in ergosterol biosynthesis upon exposure to DMIs (MacPherson et al., 2005). Likewise, the Saccharomyces cerevisiae transcriptional activators Upc2p and Ecm 22p positively regulate the expression of ergosterol biosynthesis genes (Vik and Rine, 2001). In our study, we identified several transcription factors induced in response to tetraconazole (Tables 1 and 2). Although it is currently not possible to fully characterize these genes with gene replacement studies (discussed below), it will be interesting to investigate whether these transcription factors regulate expression of ergosterol biosynthesis genes in C. beticola.

Similar to DMI exposure, cellular oxygen deficiency has been shown to induce ergosterol biosynthesis genes. For example, several ergosterol biosynthesis genes were up-regulated in the rice blast fungus Magnaporthe oryzae in response to hypoxia (Choi et al., 2015). Another example of fungal response to hypoxia is the induction of the sterol regulatory element-binding protein (SREBP) pathway, which induces ergosterol biosynthesis and hyphal growth in order to scavenge more oxygen in human fungal pathogens (Hughes et al., 2005). SREBPs are transcription factors that are activated when sterols are depleted due to triggers such as hypoxia and iron limitation (Blatzer et al., 2011). Active SREBP turns on the expression of sterol synthesis enzymes and other oxygen-dependent proteins (Blatzer et al., 2011; Choi et al., 2015). Recently, Liu et al. (2015) identified a novel SREBP gene (sreA) that was required for DMI-resistance and Cyp51 expression in Penicillium digitatum. In our study, we also identified a gene encoding SREBP induced along with ergosterol biosynthesis genes in both strains (Table 1), perhaps suggesting that oxygen is limiting and/or ergosterol deficiency is sensed in C. beticola cells upon DMI 
exposure. Ergosterol biosynthesis is thought to be impaired under hypoxic conditions because of decreased synthesis of heme and heme-containing proteins (Manente and Ghislain, 2009). Hypoxia and heme-deficiency are also known to induce RTA1 expression (Protchenko et al., 2008), which was the most highly-induced gene in the DMI-resistant strain in our study (Table 2). The RTA1 gene was originally identified during a screen for genes that confer resistance to the sterol biosynthesis inhibitor 7-aminocholesterol in S. cerevisiae (Soustre et al., 1996). RTA1 proteins encode a protein with six or seven transmembrane spans (Manente and Ghislain, 2009). Although the function of RTA1 is not fully understood, RTA1 is not thought to be involved with efflux of 7-aminocholesterol and S. cerevisiae null mutants are still viable under normal growth conditions (Soustre et al., 1996). Recent evidence suggests several gene networks involved with diverse cellular responses including hypoxia, responses to some cytotoxic drugs, and ergosterol biosynthesis converge at the promoter of the RTA1 gene (Kołaczkowska et al., 2012), suggesting that RTA1 is involved with the response to various stresses perhaps by fortifying the cell membrane. Similar to S. cerevisiae (Manente and Ghislain, 2009), the $C$. beticola genome encodes nine RTA1-like proteins that are similar only on the amino acid level (de Jonge and Bolton, unpublished). Taken together, this may suggest that functional redundancy of RTA1 is necessary to ready the cell for a variety of stresses.

The basic protocol for transformation of fungal protoplasts by the addition of a high concentration of polyethylene glycol (PEG) is well-established and remains the most common method to conduct transformation in filamentous fungi (Liu and Friesen, 2012). In our study, we used PEG-mediated transformation of protoplasts to introduce constructs to remove genes putatively associated with DMIresistance. Surprisingly, DMI-resistance as measured by $\mathrm{EC}_{50}$ value was significantly increased in all mutants generated in this study regardless of the target gene or whether the integration was sitedirected or ectopic (Table 3). To further characterize this phenomenon, we generated mutants in two other strains and found that $\mathrm{EC}_{50}$ values increased in both. This may suggest that $C$. beticola responds to 
protoplast formation in the transformation process with a new cell wall that is particularly fortified, which results in enhanced DMI-resistance. Likewise, the cell membrane may be modified as a result of PEG exposure which results in increased DMI resistance. To our knowledge, this phenomenon has not been described in filamentous fungi. Since there are no other reported transformation alternatives for C. beticola, future research directed towards developing an Agrobacterium tumefaciens-based transformation protocol will be necessary to characterize genes associated with DMI resistance in this pathogen.

In conclusion, we used next generation sequencing to compare the response of two strains contrasting with DMI-resistance in the sugar beet pathogen C. beticola. The genes induced in response to tetraconazole highlight the important role that the cell membrane plays in DMI-resistance. This is further supported by our finding that mutants generated from C. beticola protoplasts exhibited higher DMI-resistance than progenitor strains. Future studies directed at dissecting particular cell-wall and membrane components specifically involved with tetraconazole resistance will be of particular interest to understand DMI resistance in this pathosystem. 


\section{Acknowledgements}

We thank Keshav Birla and Jon Neubauer (USDA-ARS) for excellent technical assistance. M. D. Bolton is supported by USDA-ARS CRIS project 3060-22000-047-00 and grants from the Beet Sugar Development Foundation and the Sugar beet Research and Education Board of MN and ND. 


\section{REFERENCES}

Ashburner, M., Ball, C. A., Blake, J. A., Botstein, D., Butler, H., Cherry, J. M., Davis, A. P., Dolinski, K., Dwight, S. S., Eppig, J. T., 2000. Gene Ontology: tool for the unification of biology. Nat. Genet. 25, 25-29.

Augstein, A., Barth, K., Gentsch, M., Kohlwein, S. D., Barth, G., 2003. Characterization, localization and functional analysis of Gpr1p, a protein affecting sensitivity to acetic acid in the yeast Yarrowia lipolytica. Microbiology. 149, 589-600.

Birla, K., Rivera-Varas, V., Secor, G. A., Khan, M. F. R., Bolton, M. D., 2012. Characterization of cytochrome $b$ from European field isolates of Cercospora beticola with quinone outside inhibitor resistance. Eur. J. Plant Pathol. 134, 475-488.

Blatzer, M., Barker, B. M., Willger, S. D., Beckmann, N., Blosser, S. J., Cornish, E. J., Mazurie, A., Grahl, N., Haas, H., Cramer, R. A., 2011. SREBP coordinates iron and ergosterol homeostasis to mediate triazole drug and hypoxia responses in the human fungal pathogen Aspergillus fumigatus. PLoS Genet. 7, e1002374.

Bolton, M. D., Birla, K., Rivera-Varas, V., Rudolph, K., Secor, G. A., 2012a. Characterization of CbCyp51 from field isolates of Cercospora beticola. Phytopathol. 102, 298-305.

Bolton, M. D., de Jonge, R., Inderbitzin, P., Liu, Z., Birla, K., Van de Peer, Y., Subbarao, K. V., Thomma, B. P. H. J., Secor, G. A., 2014. The heterothallic sugarbeet pathogen Cercospora beticola contains exon fragments of both MAT genes that are homogenized by concerted evolution. Fungal Genet. Biol. 62, 43-54.

Bolton, M. D., Rivera-Varas, V., del Río Mendoza, L. E., Khan, M. F. R., Secor, G. A., 2012b. Efficacy of variable tetraconazole rates against Cercospora beticola isolates with differing in vitro sensitivities to DMI fungicides. Plant Dis. 96, 1749-1756.

Bolton, M. D., Rivera-Varas, V., Secor, G. A., Cattanach, A. W., Metzger, M. S., 2013a. Identification of the G143A mutation in cytochrome b associated with $Q_{0}$ l resistance in Cercospora beticola isolates from the Red River Valley. Plant Health Progress.

Bolton, M. D., Rivera, V., Secor, G., 2013b. Identification of the G143A mutation associated with Qol resistance in Cercospora beticola field isolates from Michigan, United States. Pest Manag. Sci. 69, 35-39.

Bolton, M. D., Secor, G. A., Rivera, V., Weiland, J. J., Rudolph, K., Birla, K., Rengifo, J., Campbell, L. G., 2012c. Evaluation of the potential for sexual reproduction in field populations of Cercospora beticola from USA. Fungal Biol. 116, 511-521.

Bowman, S. M., Free, S. J., 2006. The structure and synthesis of the fungal cell wall. BioEssays. 28, 799808.

Bradshaw, R. E., Slot, J. C., Moore, G. G., Chettri, P., de Wit, P. J. G. M., Ehrlich, K. C., Ganley, A. R. D., Olson, M. A., Rokas, A., Carbone, I., Cox, M. P., 2013. Fragmentation of an aflatoxin-like gene cluster in a forest pathogen. New Phytol. 198, 525-535.

Brown, D. W., Yu, J. H., Kelkar, H. S., Fernandes, M., Nesbitt, T. C., Keller, N. P., Adams, T. H., Leonard, T. J., 1996. Twenty-five coregulated transcripts define a sterigmatocystin gene cluster in Aspergillus nidulans. Proc. Natl. Acad. Sci. U. S. A. 93, 1418-1422.

Carter, H. E., Fraaije, B. A., West, J. S., Kelly, S. L., Mehl, A., Shaw, M. W., Cools, H. J., 2014. Alterations in the predicted regulatory and coding regions of the sterol 14 $\alpha$-demethylase gene (CYP51) confer decreased azole sensitivity in the oilseed rape pathogen Pyrenopeziza brassicae. Mol. Plant Pathol. 15, 513-522.

Catlett, N. L., Lee, B. N., Yoder, O. C., Turgeon, B. G., 2003. Split-marker recombination for efficient targeted deletion of fungal genes. Fungal Genetics Reports. 50, 9-11. 
Choi, J., Chung, H., Lee, G.-W., Koh, S.-K., Chae, S.-K., Lee, Y.-H., 2015. Genome-wide analysis of hypoxiaresponsive genes in the rice blast fungus, Magnaporthe oryzae. PLoS ONE. 10, e0134939.

Cools, H. J., Bayon, C., Atkins, S., Lucas, J. A., Fraaije, B. A., 2012. Overexpression of the sterol $14 \alpha-$ demethylase gene (MgCYP51) in Mycosphaerella graminicola isolates confers a novel azole fungicide sensitivity phenotype. Pest Manag. Sci. 68, 1034-1040.

Cools, H. J., Fraaije, B. A., Bean, T. P., Antoniw, J., Lucas, J. A., 2007. Transcriptome profiling of the response of Mycosphaerella graminicola isolates to an azole fungicide using cDNA microarrays. Mol. Plant Pathol. 8, 639-651.

Cools, H. J., Hawkins, N. J., Fraaije, B. A., 2013. Constraints on the evolution of azole resistance in plant pathogenic fungi. Plant Pathol. 62, 1-7.

Cools, H. J., Parker, J. E., Kelly, D. E., Lucas, J. A., Fraaije, B. A., Kelly, S. L., 2010. Heterologous expression of mutated eburicol 14 $\alpha$-demethylase (CYP51) proteins of Mycosphaerella graminicola to assess effects on azole fungicide sensitivity and intrinsic protein function. Appl. Environ. Microbiol. 76, 2866-2872.

Daub, M. E., Ehrenshaft, M., 2000. The photoactivated Cercospora toxin cercosporin: contributions to plant disease and fundamental biology. Annu. Rev. Phytopathol. 38, 461-490.

De Backer, M. D., Ilyina, T., Ma, X.-J., Vandoninck, S., Luyten, W. H. M. L., Vanden Bossche, H., 2001. Genomic profiling of the response of Candida albicans to itraconazole treatment using a DNA microarray. Antimicrob. Agents Chemother. 45, 1660-1670.

Dobin, A., Davis, C. A., Schlesinger, F., Drenkow, J., Zaleski, C., Jha, S., Batut, P., Chaisson, M., Gingeras, T. R., 2013. STAR: ultrafast universal RNA-seq aligner. Bioinformatics. 29, 15-21.

Dunkel, N., Liu, T. T., Barker, K. S., Homayouni, R., Morschhäuser, J., Rogers, P. D., 2008. A gain-offunction mutation in the transcription factor Upc2p causes upregulation of ergosterol biosynthesis genes and increased fluconazole resistance in a clinical Candida albicans isolate. Eukaryot. Cell. 7, 1180-1190.

Finn, R. D., Bateman, A., Clements, J., Coggill, P., Eberhardt, R. Y., Eddy, S. R., Heger, A., Hetherington, K., Holm, L., Mistry, J., Sonnhammer, E. L. L., Tate, J., Punta, M., 2014. Pfam: the protein families database. Nucleic Acids Res. 42, D222-D230.

Franc, G. D., Ecology and epidemiology of Cercospora beticola. In: R. T. Lartey, et al., Eds.), Cercospora leaf spot of sugar beet and related species. The American Phytopathological Society, St. Paul, Minnesota, 2010, pp. 7-19.

Friesen, T. L., Faris, J. D., Characterization of plant-fungal interactions involving necrotrophic effectorproducing plant pathogens. In: M. D. Bolton, B. P. H. J. Thomma, Eds.), Plant Fungal Pathogens: Methods and Protocols. Springer, 2012, pp. 191-207.

Friesen, T. L., Stukenbrock, E. H., Liu, Z., Meinhardt, S., Ling, H., Faris, J. D., Rasmussen, J. B., Solomon, P. S., McDonald, B. A., Oliver, R. P., 2006. Emergence of a new disease as a result of interspecific virulence gene transfer. Nat. Genet. 38, 953-956.

Fulton, T. M., Chunwongse, J., Tanksley, S. D., 1995. Microprep protocol for extraction of DNA from tomato and other herbaceous plants. Plant Mol. Biol. Report. 13, 207-207.

Goswami, R., Targeted Gene Replacement in Fungi Using a Split-Marker Approach. In: M. D. Bolton, B. P. H. J. Thomma, Eds.), Plant Fungal Pathogens. Humana Press, 2012, pp. 255-269.

Hamamoto, H., Hasegawa, K., Nakaune, R., Lee, Y. J., Makizumi, Y., Akutsu, K., Hibi, T., 2000. Tandem repeat of a transcriptional enhancer upstream of the sterol 14alpha-demethylase gene (CYP51) in Penicillium digitatum. Appl. Environ. Microbiol. 66, 3421.

Hughes, A. L., Todd, B. L., Espenshade, P. J., 2005. SREBP pathway responds to sterols and functions as an oxygen sensor in fission yeast. Cell. 120, 831-842.

Khan, J., del Río, L. E., Nelson, R., Khan, M. F. R., 2007. Improving the Cercospora leaf spot management model for sugar beet in Minnesota and North Dakota. Plant Dis. 91, 1105-1108. 
Khan, J., Rio, L. E. d., Nelson, R., Rivera-Varas, V., Secor, G. A., Khan, M. F. R., 2008. Survival, dispersal, and primary infection site for Cercospora beticola in sugar beet. Plant Dis. 92, 741-745.

Kołaczkowska, A., Manente, M., Kołaczkowski, M., Laba, J., Ghislain, M., Wawrzycka, D., 2012. The regulatory inputs controlling pleiotropic drug resistance and hypoxic response in yeast converge at the promoter of the aminocholesterol resistance gene RTA1. FEMS Yeast Res. 12, 279-292.

Kretschmer, M., Leroch, M., Mosbach, A., Walker, A.-S., Fillinger, S., Mernke, D., Schoonbeek, H.-J., Pradier, J.-M., Leroux, P., De Waard, M. A., Hahn, M., 2009. Fungicide-driven evolution and molecular basis of multidrug resistance in field populations of the grey mould fungus Botrytis cinerea. PLoS Pathog. 5, e1000696.

Lah, L., Kraševec, N., Trontelj, P., Komel, R., 2008. High diversity and complex evolution of fungal cytochrome P450 reductase: Cytochrome P450 systems. Fungal Genet. Biol. 45, 446-458.

Lartey, R. T., Caesar-TonThat, T. C., Caesar, A. J., Shelver, W. L., Sol, N. I., Bergman, J. W., 2005. Safflower: A New Host of Cercospora beticola. Plant Dis. 89, 797-801.

Lendenmann, M. H., Croll, D., McDonald, B. A., 2015. QTL mapping of fungicide sensitivity reveals novel genes and pleiotropy with melanization in the pathogen Zymoseptoria tritici. Fungal Genet. Biol. 80, 53-67.

Leroux, P., Albertini, C., Gautier, A., Gredt, M., Walker, A.-S., 2007. Mutations in the CYP51 gene correlated with changes in sensitivity to sterol $14 \alpha$-demethylation inhibitors in field isolates of Mycosphaerella graminicola. Pest Manag. Sci. 63, 688-698.

Liu, J., Yuan, Y., Wu, Z., Li, N., Chen, Y., Qin, T., Geng, H., Xiong, L., Liu, D., 2015. A novel sterol regulatory element-binding protein gene sreA identified in Penicillium digitatum is required for prochloraz resistance, full virulence and erg11 (cyp51) regulation. PLoS ONE. 10, e0117115.

Liu, T. T., Lee, R. E. B., Barker, K. S., Lee, R. E., Wei, L., Homayouni, R., Rogers, P. D., 2005. Genome-wide expression profiling of the response to azole, polyene, echinocandin, and pyrimidine antifungal agents in Candida albicans. Antimicrob. Agents Chemother. 49, 2226-2236.

Liu, Z., Friesen, T. L., Polyethylene glycol (PEG)-mediated transformation in filamentous fungal pathogens. In: M. D. Bolton, B. P. H. J. Thomma, Eds.), Plant Fungal Pathogens: Methods and Protocols. Springer, 2012, pp. 365-375.

Ma, B., Tredway, L. P., 2013. Induced overexpression of cytochrome P450 sterol $14 \alpha$-demethylase gene (CYP51) correlates with sensitivity to demethylation inhibitors (DMIs) in Sclerotinia homoeocarpa. Pest Manag. Sci. 69, 1369-1378.

Ma, Z., Proffer, T. J., Jacobs, J. L., Sundin, G. W., 2006. Overexpression of the $14 \alpha$-demethylase target gene (CYP51) mediates fungicide resistance in Blumeriella jaapii. Appl. Environ. Microbiol. 72, 2581-2585.

MacPherson, S., Akache, B., Weber, S., De Deken, X., Raymond, M., Turcotte, B., 2005. Candida albicans zinc cluster protein Upc2p confers resistance to antifungal drugs and is an activator of ergosterol biosynthetic genes. Antimicrob. Agents Chemother. 49, 1745-1752.

Manente, M., Ghislain, M., 2009. The lipid-translocating exporter family and membrane phospholipid homeostasis in yeast. FEMS Yeast Res. 9, 673-687.

Meyer, V., Damveld, R. A., Arentshorst, M., Stahl, U., van den Hondel, C. A. M. J. J., Ram, A. F. J., 2007. Survival in the presence of antifungals: genome-wide expression profiling of Aspergillus niger in response to sublethal concentrations of caspofungin and fenpropimorph. J. Biol. Chem. 282, 32935-32948.

Mitchell, A., Chang, H.-Y., Daugherty, L., Fraser, M., Hunter, S., Lopez, R., McAnulla, C., McMenamin, C., Nuka, G., Pesseat, S., Sangrador-Vegas, A., Scheremetjew, M., Rato, C., Yong, S.-Y., Bateman, A., Punta, M., Attwood, T. K., Sigrist, C. J. A., Redaschi, N., Rivoire, C., Xenarios, I., Kahn, D., Guyot, D., Bork, P., Letunic, I., Gough, J., Oates, M., Haft, D., Huang, H., Natale, D. A., Wu, C. H., Orengo, 
C., Sillitoe, I., Mi, H., Thomas, P. D., Finn, R. D., 2014. The InterPro protein families database: the classification resource after 15 years. Nucleic Acids Res.

Panagabko, C., Morley, S., Hernandez, M., Cassolato, P., Gordon, H., Parsons, R., Manor, D., Atkinson, J., 2003. Ligand Specificity in the CRAL-TRIO Protein Family. Biochemistry. 42, 6467-6474.

Panella, L., 2010. Sugar beet as an energy crop. Sugar Tech. 12, 288-293.

Protchenko, O., Shakoury-Elizeh, M., Keane, P., Storey, J., Androphy, R., Philpott, C. C., 2008. Role of PUG1 in inducible porphyrin and heme transport in Saccharomyces cerevisiae. Eukaryot. Cell. 7, 859-871.

Roberts, A., Pimentel, H., Trapnell, C., Pachter, L., 2011. Identification of novel transcripts in annotated genomes using RNA-Seq. Bioinformatics. 27, 2325-2329.

Roohparvar, R., Mehrabi, R., Van Nistelrooy, J. G., Zwiers, L. H., De Waard, M. A., 2008. The drug transporter MgMfs1 can modulate sensitivity of field strains of the fungal wheat pathogen Mycosphaerella graminicola to the strobilurin fungicide trifloxystrobin. Pest Manag. Sci.

Schnabel, G., Jones, A. L., 2001. The 14 $\alpha$-demethylase (CYP51A1) gene is overexpressed in Venturia inaequalis strains resistant to myclobutanil. Phytopathol. 91, 102-110.

Secor, G. A., Rivera, V. V., Fungicide resistance assays for fungal plant pathogens. In: M. D. Bolton, B. P. H. J. Thomma, Eds.), Plant Fungal Pathogens: Methods and Protocols. Humana Press, New York, 2012, pp. 385-392.

Secor, G. A., Rivera, V. V., Khan, M. F. R., Gudmestad, N. C., 2010. Monitoring fungicide sensitivity of Cercospora beticola of sugar beet for disease management decisions. Plant Dis. 94, 1272-1282.

Šimová, Z., Poloncová, K., Tahotná, D., Holič, R., Hapala, I., Smith, A. R., White, T. C., Griač, P., 2013. The yeast Saccharomyces cerevisiae Pdr16p restricts changes in ergosterol biosynthesis caused by the presence of azole antifungals. Yeast. 30, 229-241.

Soustre, I., Letourneux, Y., Karst, F., 1996. Characterization of the Saccharomyces cerevisiae RTA1 gene involved in 7-aminocholesterol resistance. Curr. Genet. 30, 121-125.

Steinkamp, M. P., Martin, S. S., Hoefert, L. L., Ruppel, E. G., 1979. Ultrastructure of lesions produced by Cercospora beticola in leaves of Beta vulgaris. Physiol. Plant Pathol. 15, 13-26.

Sun, X., Xu, Q., Ruan, R., Zhang, T., Zhu, C., Li, H., 2013. PdMLE1, a specific and active transposon acts as a promoter and confers Penicillium digitatum with DMI resistance. Environmental Microbiology Reports. 5, 135-142.

Thomma, B. P. H. J., Seidl, M. F., Shi-Kunne, X., Cook, D., Bolton, M. D., Van Kan, J. A. L., Faino, L., 2015. Mind the gap; seven reasons to close fragmented genome assemblies. Fungal Genet. Biol.

Tritt, A., Eisen, J. A., Facciotti, M. T., Darling, A. E., 2012. An integrated pipeline for de novo assembly of microbial genomes. PLoS One. 7, e42304.

Vik, Å., Rine, J., 2001. Upc2p and Ecm22p, dual regulators of sterol biosynthesis in Saccharomyces cerevisiae. Mol. Cell. Biol. 21, 6395-6405.

Weiland, J. J., Halloin, J. M., 2001. Benzimidazole resistance in Cercospora beticola sampled from sugarbeet fields in Michigan, USA. Can. J. Plant Pathol. 23, 78-82.

$\mathrm{Wu}, \mathrm{T}$. D., Nacu, S., 2010. Fast and SNP-tolerant detection of complex variants and splicing in short reads. Bioinformatics. 26, 873-881.

Zwiers, L.-H., Stergiopoulos, I., Van Nistelrooy, J. G. M., De Waard, M. A., 2002. ABC transporters and azole susceptibility in laboratory strains of the wheat pathogen Mycosphaerella graminicola. Antimicrob. Agents Chemother. 46, 3900-3906. 
Table 1. Differentially-expressed genes ${ }^{1}$ identified in both DMI-sensitive (09-32) and -resistant (10-73-4) Cercospora beticola strains after exposure to tetraconazole.

\begin{tabular}{|c|c|c|c|c|c|c|c|}
\hline \multirow[b]{2}{*}{ Gene } & \multirow[b]{2}{*}{ Predicted function } & \multicolumn{2}{|c|}{$\log _{2} \mathrm{FC}$} & \multirow[b]{2}{*}{ E-value } & \multirow[b]{2}{*}{ Accession } & \multirow[b]{2}{*}{ InterPro } & \multirow[b]{2}{*}{ PFAM } \\
\hline & & $09-32$ & $10-73-4$ & & & & \\
\hline \multicolumn{8}{|c|}{ ATP binding (GO:0005524) } \\
\hline CBET3_05020-RA & AAA family ATPase & -2.39 & -2.19 & 0.0 & XP_007600097 & IPR003959 & PF00004 \\
\hline CBET3_11559-RA & AAA family ATPase & 2.29 & 1.83 & 0.0 & EMF10161 & IPR003959 & PF00004 \\
\hline CBET3_09831-RA & $A B C$ transporter, $A B C-B$ family, MDR type & 2.29 & 2.21 & 0.0 & XP_007927232 & IPR003439 & PF00005 \\
\hline CBET3_05101-RA & P-loop containing nucleoside triphosphate hydrolase & -1.82 & -1.88 & 0.0 & EMF08438 & IPR003959 & PF00004 \\
\hline \multicolumn{8}{|c|}{ Biological process (GO:0008150) } \\
\hline CBET3_00433-RA & FAD/NAD-P-binding domain-containing protein & 1.55 & 1.37 & 8.35E-64 & KJX96668 & IPR002938 & \\
\hline \multicolumn{8}{|c|}{ Biosynthetic process (GO:0009058) } \\
\hline CBET3_01606-RA & Squalene synthase (ERG9) & 2.63 & 2.08 & 0.0 & EMF16463 & IPR002060 & PF00494 \\
\hline CBET3_09638-RA & Polyketide synthase & -2.54 & 1.99 & 0.0 & XP_003848644 & IPR001031 & PF00975 \\
\hline \multicolumn{8}{|c|}{ Carbohydrate metabolic process (GO:0005975) } \\
\hline CBET3_07796-RA & Glycoside hydrolase family 16 protein & -1.47 & -1.57 & $9 \mathrm{E}-75$ & XP_007930006 & IPR000757 & PF00722 \\
\hline CBET3_08404-RA & Glycoside hydrolase family 29 protein & 3.98 & 3.13 & 0.0 & KEQ97150 & IPR000933 & PF01120 \\
\hline \multicolumn{8}{|c|}{ Catalytic activity (GO:0003824) } \\
\hline CBET3_09907-RA & Lanosterol synthase (ERG7) & 3.65 & 3.41 & 0.0 & XP_003850188 & IPR001330 & PF00432 \\
\hline \multicolumn{8}{|c|}{ Coenzyme A biosynthetic process (GO:0015937) } \\
\hline CBET3_06021-RA & Pantothenate kinase & 1.69 & 2.29 & 0.0 & KEQ64276 & IPR004567 & PF03630 \\
\hline \multicolumn{8}{|c|}{ Fatty acid biosynthetic process (GO:0006633) } \\
\hline CBET3_06384-RA & Methylsterol monooxygenase (ERG25) & 2.74 & 3.08 & 0.0 & XP_003854964 & IPR006694 & PF04116 \\
\hline CBET3_09933-RA & C-5 sterol desaturase (ERG3) & 3.31 & 2.82 & 0.0 & KEQ58244 & IPR006694 & PF04116 \\
\hline \multicolumn{8}{|c|}{ Hydrolase activity, acting on carbon-nitrogen (but not peptide) bonds (GO:0016810) } \\
\hline CBET3_03701-RA & Cyanide hydratase & 2.75 & 1.98 & 0.0 & CDM33757 & IPR000132 & PF00795 \\
\hline \multicolumn{8}{|c|}{ Integral component of membrane (GO:0016021) } \\
\hline CBET3_07811-RA & DUF887-domain-containing protein & 1.61 & 1.42 & 0.0 & EMF14457 & IPR006634 & PF03798 \\
\hline CBET3_10695-RA & Potassium/sodium efflux P-type ATPase like protein & -2.09 & -1.52 & 0.0 & KJX92451 & IPR001757 & \\
\hline CBET3_00214-RA & Sterol regulatory element-binding protein cleavage-activating & 2.25 & 2.42 & 0.0 & KJX95407 & IPR000731 & \\
\hline \multicolumn{8}{|c|}{ Isoprenoid biosynthetic process (GO:0008299) } \\
\hline CBET3_09160-RA & Farnesyl diphosphate synthase (FDS) & 2.23 & 2.38 & 0.0 & XP_003850094 & IPR000092 & PF00348 \\
\hline CBET3_06225-RA & Hydroxymethylglutaryl-CoA synthase (ERG13) & 3.45 & 2.85 & 0.0 & EMF11041 & IPR010122 & PF01154 \\
\hline
\end{tabular}




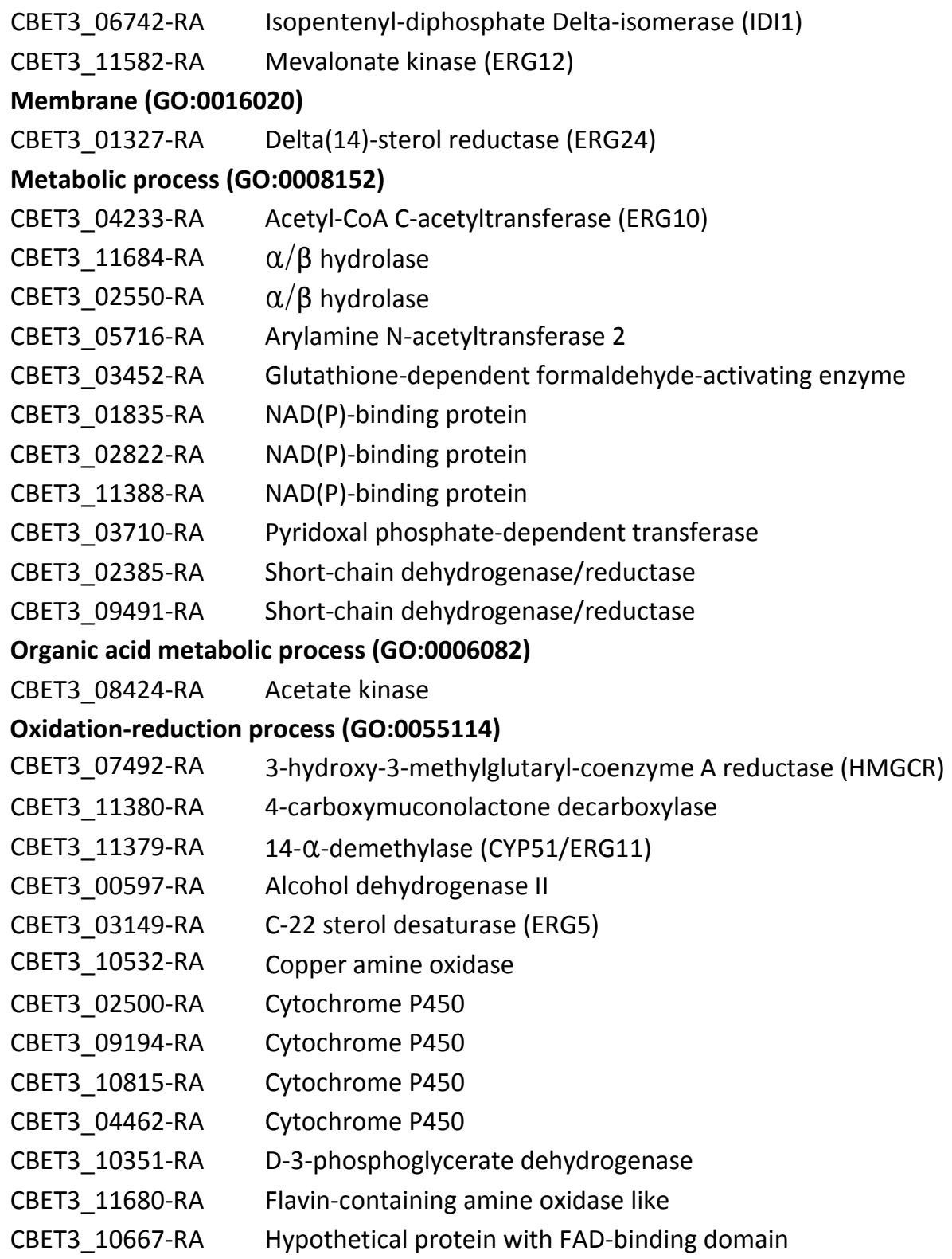

\begin{tabular}{|c|c|c|c|c|c|}
\hline 1.73 & 2.09 & 0.0 & EMF09571 & IPR011876 & \\
\hline 2.58 & 1.92 & 0.0 & EMF10221 & IPR006205 & \\
\hline 4.28 & 4.10 & 0.0 & EMF17378 & IPR001171 & PF01222 \\
\hline 3.28 & 3.52 & 0.0 & XP_003852634 & IPR002155 & \\
\hline 5.21 & 5.88 & $2 E-164$ & KJX97729 & IPR013094 & PF07859 \\
\hline 4.55 & 1.54 & 0.0 & EMF15641 & IPR013094 & PF07859 \\
\hline-1.98 & -1.61 & $25 \mathrm{E}-174$ & CBL43313 & IPR00144 & PF00797 \\
\hline 4.24 & 3.25 & $1 \mathrm{E}-18$ & EQB44398 & IPR006913 & PF04828 \\
\hline 4.85 & 5.15 & 24E-151 & EMF16324 & IPR002198 & PF00106 \\
\hline-4.23 & 1.52 & $7 E-174$ & KEQ67599 & IPR002198 & PF00106 \\
\hline-2.10 & 2.25 & $3 E-103$ & KEQ60389 & IPR002198 & PF00106 \\
\hline-1.58 & -1.84 & 0.0 & EMF15374 & IPR000192 & PF00266 \\
\hline 6.29 & 6.26 & $1 \mathrm{E}-75$ & WP_026299182 & IPR002198 & PF00106 \\
\hline 1.93 & 2.03 & $4 \mathrm{E}-170$ & EKG11072 & IPR002198 & PF00106 \\
\hline 1.98 & 2.17 & 0.0 & EMF13292 & IPR004372 & \\
\hline 1.52 & 1.68 & 0.0 & EMF14786 & IPR002202 & PF00368 \\
\hline 3.20 & 4.56 & $39 E-98$ & KJX97620 & IPR003779 & PF02627 \\
\hline 5.10 & 3.57 & 0.0 & AEU04152 & IPR001128 & PF00067 \\
\hline 3.93 & 2.58 & 0.0 & EMF17075 & IPR002085 & PF08240 \\
\hline 3.30 & 2.65 & 0.0 & XP_003855007 & IPR001128 & PF00067 \\
\hline-1.75 & -1.77 & 0.0 & EKG14169 & IPR000269 & PF01179 \\
\hline 2.06 & 2.21 & $1 E-168$ & XP_008596070 & IPR001128 & PF00067 \\
\hline 4.41 & 5.35 & 0.0 & EMF12198 & IPR001128 & PF00067 \\
\hline 2.49 & 3.13 & 0.0 & EMF12954 & IPR001128 & PF00067 \\
\hline 6.15 & 3.05 & $2 \mathrm{E}-163$ & XP_007581051 & IPR001128 & PF00067 \\
\hline 1.96 & 1.43 & $1 \mathrm{E}-116$ & GAD98572 & IPR006140 & PF02826 \\
\hline 3.16 & 4.03 & 0.0 & KJX96742 & IPR001613 & PF01593 \\
\hline 2.69 & 6.73 & 0.0 & KJX98909 & IPR016166 & \\
\hline
\end{tabular}




\begin{tabular}{|c|c|c|c|c|c|c|c|}
\hline CBET3_11975-RA & Hypothetical protein with oxidoreductase domain & -1.87 & -2.52 & $1 \mathrm{E}-147$ & KJX96592 & IPR005123 & PF13640 \\
\hline CBET3_11351-RA & O-methylsterigmatocystin oxidoreductase & -3.14 & 3.37 & 0.0 & GAM33870 & IPR001128 & PF00067 \\
\hline CBET3_08405-RA & Squalene monooxygenase (ERG1) & 2.00 & 2.20 & 0.0 & XP_003854443 & IPR013698 & PF08491 \\
\hline CBET3_11355-RA & Zn-dependent oxidoreductase & -2.99 & 2.59 & $4 \mathrm{E}-72$ & WP_042369849 & IPR013149 & PF00107 \\
\hline \multicolumn{8}{|c|}{ Oxidoreductase (GO:0016491) } \\
\hline CBET3_01462-RA & L-lactate dehydrogenase & 1.92 & 1.70 & 0.0 & EMF17491 & IPR000262 & PF01070 \\
\hline CBET3_09636-RA & Tetrahydroxynaphthalene reductase & -4.25 & 1.32 & $1 \mathrm{E}-136$ & XP_007931484 & IPR002198 & PF00106 \\
\hline \multicolumn{8}{|c|}{ Phosphopantetheine binding (GO:0031177) } \\
\hline CBET3_11350-RA & Polyketide synthase & -3.74 & 2.79 & 0.0 & AAR92210 & IPR020806 & \\
\hline \multicolumn{8}{|c|}{ Protein binding (GO:0005515) } \\
\hline CBET3_04298-RA & Dihydroxyacid dehydratase & -1.91 & -1.81 & 0.0 & EQB43606 & IPR001841 & \\
\hline CBET3_08724-RA & F-box domain protein & -1.43 & -1.98 & 0.0 & KJX95423 & IPR001810 & \\
\hline CBET3_10269-RA & Galactose oxidase & 1.90 & 2.34 & 0.0 & EMF13012 & IPR006652 & \\
\hline CBET3_11629-RA & Glutathione s-transferase & 3.94 & 3.76 & $1 \mathrm{E}-51$ & XP_007581437 & IPR004045 & PF13417 \\
\hline CBET3_11956-RA & Glutathione s-transferase & 3.24 & 3.27 & $2 \mathrm{E}-107$ & KJX95768 & IPR004045 & PF13417 \\
\hline CBET3_04747-RA & Thioredoxin reductase & 2.22 & 1.37 & 0.0 & EMF13895 & IPR001327 & PF07992 \\
\hline \multicolumn{8}{|c|}{ Protein dimerization activity (GO:0046983) } \\
\hline CBET3_00556-RA & Sterol regulatory element binding protein sre1 & 3.26 & 2.63 & 0.0 & XP_007579378 & IPR011598 & \\
\hline \multicolumn{8}{|c|}{ Proteolysis (GO:0006508) } \\
\hline CBET3_04384-RA & Metallopeptidase MepB like protein & 2.24 & 1.95 & 0.0 & KJX93553 & IPR001567 & PF01432 \\
\hline CBET3_05080-RA & Serine carboxypeptidase & -1.89 & -1.45 & 0.0 & KJX94244 & IPR001563 & \\
\hline CBET3_02384-RA & zinc carboxypeptidase like & 4.05 & 3.56 & $8 \mathrm{E}-142$ & KJX93403 & & \\
\hline \multicolumn{8}{|c|}{ Pyridoxal phosphate binding (GO:0030170) } \\
\hline CBET3_04693-RA & 2,2-dialkylglycine decarboxylase & -4.33 & -1.79 & 0.0 & AAM18795 & IPR005814 & \\
\hline CBET3_09485-RA & Hypothetical protein with MOSC N-terminal beta barrel domain & 1.76 & 1.53 & 0.0 & EMF11755 & IPR005302 & PF03473 \\
\hline \multicolumn{8}{|c|}{ Regulation of transcription, DNA-templated (GO:0006355) } \\
\hline CBET3_05836-RA & bZIP transcription factor & 1.66 & 1.80 & $9 \mathrm{E}-138$ & XP_007922535 & IPR004827 & PF00170 \\
\hline CBET3_09356-RA & $\mathrm{Zn}(\mathrm{II})_{2} \mathrm{Cys}_{6}$ fungal-type transcription factor & 2.04 & 2.01 & $1 \mathrm{E}-125$ & EMF12171 & IPR001138 & PF00172 \\
\hline \multicolumn{8}{|c|}{ Self proteolysis (GO:0097264) } \\
\hline CBET3_00643-RA & RHS Repeat protein & 2.93 & 3.57 & 0.0 & GAD94323 & IPR022385 & \\
\hline \multicolumn{8}{|c|}{ Steroid biosynthetic process (GO:0006694) } \\
\hline CBET3_06157-RA & Sterol 24-C-methyltransferase (ERG6) & 4.84 & 4.00 & 0.0 & EMF11257.1 & IPR013705 & PF08498 \\
\hline
\end{tabular}


Transcription, DNA-templated (GO:0006351)

\begin{tabular}{|c|c|c|c|c|c|c|c|}
\hline CBET3_08827-RA & Transcription elongation factor S-II & 4.86 & 3.34 & $1 E-29$ & EMR80493 & IPR003618 & PF07500 \\
\hline \multicolumn{8}{|c|}{ Transmembrane transport (GO:0055085) } \\
\hline CBET3_03438-RA & Cation diffusion facilitator 1 & 2.28 & 2.58 & 0.0 & KEQ77619 & IPR002524 & PF01545 \\
\hline CBET3_02677-RA & Hexose transporter-like protein & 1.94 & 3.02 & 0.0 & ENH76856 & IPR003663 & PF00083 \\
\hline CBET3_03495-RA & Lactose permease & 1.69 & 1.54 & 0.0 & XP_001933299 & IPR003663 & PF00083 \\
\hline CBET3_11354-RA & Major facilitator superfamily multidrug resistance transporter & -2.71 & 2.57 & 0.0 & XP_960834 & IPR011701 & PF07690 \\
\hline \multicolumn{8}{|c|}{ Transport (GO:0006810) } \\
\hline CBET3_08499-RA & Major intrinsic protein & 2.29 & 1.57 & 0.0 & XP_001258974 & IPR000425 & PF00230 \\
\hline \multicolumn{8}{|c|}{ Ubiquitin-dependent protein catabolic process (GO:0006511) } \\
\hline CBET3_08917-RA & Cullin repeat-containing protein & -1.70 & -1.75 & $6 \mathrm{E}-23$ & KEQ88354 & IPR001373 & PF00888 \\
\hline \multicolumn{8}{|l|}{ Unclassified } \\
\hline CBET3_11353-RA & 2-polyprenyl-6-methoxyphenol hydroxylase & -3.40 & 3.20 & 0.0 & AJW29601 & IPR002938 & PF01494 \\
\hline CBET3_08812-RA & 3-keto-steroid reductase (ERG27) & 2.43 & 2.13 & 0.0 & EMF13199 & & \\
\hline CBET3_11356-RA & AflY & -3.15 & 2.93 & $4 \mathrm{E}-143$ & ACH72894 & & \\
\hline CBET3_00169-RA & $\alpha / \beta$-hydrolase & 3.62 & 3.13 & $8 \mathrm{E}-103$ & XP_007309066 & IPR000073 & PF12697 \\
\hline CBET3_09693-RA & $\alpha / \beta$-hydrolase & 3.14 & 2.60 & $7 E-151$ & EMF12025 & IPR000073 & PF12697 \\
\hline CBET3_11622-RA & $\alpha / \beta$-hydrolase & 1.80 & 1.57 & $1 \mathrm{E}-50$ & KJX96893 & IPR000073 & PF12697 \\
\hline CBET3_00444-RA & Amino acid transporter like protein & 2.70 & 2.86 & 0.0 & KJX92975 & IPR013057 & PF01490 \\
\hline CBET3_06377-RA & $\mathrm{C}-8$ sterol isomerase (ERG2) & 4.58 & 4.74 & $2 \mathrm{E}-127$ & EMF11494.1 & IPR006716 & PF04622 \\
\hline CBET3_03624-RA & Cell wall serine-threonine-rich galactomannoprotein Mp1 & 3.34 & 2.01 & $3 \mathrm{E}-13$ & XP_746510 & IPR021054 & PF12296 \\
\hline CBET3_02310-RA & CRAL/TRIO domain-containing protein & 1.78 & 2.36 & 0.0 & EMF15692 & IPR001251 & PF00650 \\
\hline CBET3_10982-RA & Cyclohexanone monooxygenase & 4.14 & 5.85 & $3 \mathrm{E}-174$ & KKA19221 & & \\
\hline CBET3_02376-RA & DUF1768-domain-containing protein & -2.08 & -3.17 & $6 \mathrm{E}-54$ & KEQ83024 & IPR012816 & PF08719 \\
\hline CBET3_08738-RA & Enoyl-CoA hydratase & 3.88 & 5.76 & $1 \mathrm{E}-22$ & XP_001273472 & & \\
\hline CBET3_11689-RA & Flavin-binding monooxygenase-like & 4.27 & 4.19 & 0.0 & EMF14477 & & PF13738 \\
\hline CBET3_01022-RA & Glyoxalase & -2.02 & -1.49 & $8 \mathrm{E}-102$ & KJX97387 & IPR025870 & PF13468 \\
\hline CBET3_05419-RA & HAD-superfamily hydrolase like & 1.59 & 1.44 & $6 \mathrm{E}-156$ & KJX99196 & IPR006353 & PF13344 \\
\hline CBET3_02577-RA & Hypothetical protein & -2.17 & -1.88 & $1 \mathrm{E}-141$ & EMF15696 & & \\
\hline CBET3_02847-RA & Hypothetical protein & -1.61 & -2.01 & $3 \mathrm{E}-40$ & XP_007923422 & & \\
\hline CBET3_02907-RA & Hypothetical protein & 4.24 & 4.20 & $2 \mathrm{E}-109$ & EMF15962 & & \\
\hline CBET3_03327-RA & Hypothetical protein & 1.87 & 1.37 & 0.0 & EMF15447 & & \\
\hline
\end{tabular}




\begin{tabular}{|c|c|c|c|c|c|c|c|}
\hline CBET3_03903-RA & Hypothetical protein & 4.41 & 4.49 & $2 \mathrm{E}-38$ & XP_007922746 & & \\
\hline CBET3_05291-RA & Hypothetical protein & -1.86 & -1.98 & 0.0 & XP_007672588 & & \\
\hline CBET3_05777-RA & Hypothetical protein & 4.36 & 4.09 & $4 \mathrm{E}-94$ & EMF08815 & & \\
\hline CBET3_06684-RA & Hypothetical protein & 1.68 & 2.41 & 0.0 & KIW92900 & & \\
\hline CBET3_06743-RA & Hypothetical protein & 2.38 & 2.35 & $3 E-49$ & EME40860 & & \\
\hline CBET3_07300-RA & Hypothetical protein & 3.97 & 5.25 & $2 E-87$ & EMF09684 & & \\
\hline CBET3_08175-RA & Hypothetical protein & 3.06 & 2.92 & 7E-76 & EMF10381 & & \\
\hline CBET3_08918-RA & Hypothetical protein & 2.59 & 2.61 & $3 E-84$ & XP_007793395 & & \\
\hline CBET3_09355-RA & Hypothetical protein & 2.17 & 2.10 & $2 \mathrm{E}-23$ & EMF12169 & & \\
\hline CBET3_09832-RA & Hypothetical protein & 3.77 & 3.19 & 0.0 & EMF11737 & & \\
\hline CBET3_10368-RA & Hypothetical protein & 3.14 & 2.29 & $2 \mathrm{E}-89$ & EME42939 & & \\
\hline CBET3_10369-RA & Hypothetical protein & 2.87 & 2.19 & $2 \mathrm{E}-81$ & EME42938 & & \\
\hline CBET3_10412-RA & Hypothetical protein & 2.20 & 1.65 & 0.0 & EMF12762 & & \\
\hline CBET3_11736-RA & Hypothetical protein & -1.33 & -1.77 & 0.0 & NP_001135720 & & \\
\hline CBET3_11756-RA & Hypothetical protein & -1.87 & -1.83 & $1 E-52$ & EME46083 & & \\
\hline CBET3_12127-RA & Hypothetical protein & -5.65 & -2.51 & $3 E-25$ & KJX96086 & IPR029226 & PF14856 \\
\hline CBET3_09910-RA & Hypothetical protein with Rad9-like Rad53-binding domain & 2.07 & 1.61 & 0.0 & XP_007927419 & IPR013914 & PF08605 \\
\hline CBET3_11389-RA & Hypothetical protein with SnoaL-like domain & -2.89 & 2.80 & $6 \mathrm{E}-47$ & EFQ36840 & & PF13577 \\
\hline CBET3_03989-RA & Integral membrane protein & 1.81 & 1.89 & $1 \mathrm{E}-90$ & EMF10635 & IPR016964 & PF10914 \\
\hline CBET3_03405-RA & Lysine decarboxylase-like & -1.63 & -1.41 & $5 \mathrm{E}-110$ & KEQ65240 & IPR005269 & PF03641 \\
\hline CBET3_07048-RA & Mitochondrial carrier protein & 2.02 & 1.61 & $1 \mathrm{E}-137$ & EMF09651 & & \\
\hline CBET3_10011-RA & Phosphoglycerate mutase & -2.62 & -1.90 & $1 \mathrm{E}-134$ & EMF08719 & IPR013078 & PF00300 \\
\hline CBET3_03623-RA & ribose-phosphate pyrophosphokinase & 3.38 & 1.95 & $4 \mathrm{E}-145$ & XP_008602384 & IPR000073 & PF12697 \\
\hline CBET3_01326-RA & S-adenosyl-L-methionine-dependent methyltransferase & 2.48 & 2.40 & $40 E-145$ & EMF17377 & IPR029063 & PF13489 \\
\hline \multicolumn{8}{|c|}{ No annotation available } \\
\hline CBET3_01151-RA & No significant similarity & 2.82 & 2.01 & & & & \\
\hline CBET3_02311-RA & No significant similarity & 2.01 & 2.57 & & & & \\
\hline CBET3_03047-RA & No significant similarity & 3.81 & 3.59 & & & & \\
\hline CBET3_06020-RA & No significant similarity & 2.97 & 2.86 & & & & \\
\hline CBET3_06156-RA & No significant similarity & 5.53 & 4.47 & & & & \\
\hline CBET3_07294-RA & No significant similarity & 2.09 & 2.31 & & & & \\
\hline CBET3_10038-RA & No significant similarity & -2.38 & -2.94 & & & & \\
\hline
\end{tabular}


*Biological process GO term ontology was given preference when grouping genes. If no Biological Process GO term was identified for a gene, Molecular function and Cellular component GO terms were used for classification.

${ }^{1}$ Genes were considered differentially expressed if Q-values $\leq 0.001$ and $\log _{2}$ fold regulation differences $\geq 1.0$ using $t$-tests of expression values between mock- and tetraconazole-treatments for each C. beticola strain. 
Table 2. Differentially-expressed genes ${ }^{1}$ unique to Cercospora beticola DMI-resistant strain 10-73-4 after exposure to tetraconazole.

\begin{tabular}{|c|c|c|c|c|c|c|}
\hline Gene & Predicted function & $\log _{2} F C$ & E-value & Accession & InterPro & PFAM \\
\hline \multicolumn{7}{|c|}{ ATP binding (GO:0005524) } \\
\hline CBET3_00527-RA & AAA family ATPase & -1.55 & $4 \mathrm{E}-83$ & XP_007921050 & IPR003959 & PF00004 \\
\hline \multicolumn{7}{|c|}{ Biosynthetic process (GO:0009058) } \\
\hline CBET3_06542-RA & Phospho-2-dehydro-3-deoxyheptonate aldolase & -1.80 & 0.0 & EMF11415 & IPR006218 & PF00793 \\
\hline CBET3_11935-RA & Serine palmitoyl CoA transferase subunit LcbA & -2.41 & 0.0 & XP_003849027 & IPR004839 & PF00155 \\
\hline \multicolumn{7}{|c|}{ Carbohydrate metabolic process (GO:0005975) } \\
\hline CBET3_06057-RA & Beta glucan-binding protein & 1.73 & $7 \mathrm{E}-155$ & EMR86206 & IPR000757 & PF00722 \\
\hline CBET3_00682-RA & Glycoside hydrolase family 16 & 3.79 & 0.0 & EMF17292 & IPR000757 & PF00722 \\
\hline CBET3_05663-RB & Glycoside hydrolase family 16 & 3.48 & $1 E-134$ & EMF17702 & IPR000757 & PF00722 \\
\hline CBET3_01742-RA & Glycoside hydrolase family 16 & 1.85 & $6 \mathrm{E}-161$ & EMF16313 & IPR000757 & PF00722 \\
\hline CBET3_07968-RA & Glycoside hydrolase family 17 & 1.95 & $1 E-177$ & EMF13167 & IPR000490 & PF00332 \\
\hline CBET3_09944-RA & Glycoside hydrolase family 17 & 1.59 & $6 \mathrm{E}-156$ & EMF08721 & IPR000490 & \\
\hline CBET3_09115-RA & Glycoside hydrolase family 18 & 1.68 & $1 \mathrm{E}-158$ & EMF11844 & IPR001223 & PF00704 \\
\hline CBET3_10389-RA & Glycoside hydrolase family 72 & 1.95 & 0.0 & XP_007927960 & IPR004886 & PF03198 \\
\hline CBET3_00012-RA & Transaldoase & 4.38 & $1 E-157$ & KJZ775321.1 & IPR001585 & PF00923 \\
\hline \multicolumn{7}{|c|}{ Catalytic activity (GO:0003824) } \\
\hline CBET3_06881-RA & Glycoside hydrolase family 92 & -2.40 & 0.0 & EMF09713 & IPR012939 & PF07971 \\
\hline \multicolumn{7}{|c|}{ Heme binding (GO:0020037) } \\
\hline CBET3_11439-RA & Indoleamine 2,3-dioxygenase & 1.88 & 0.0 & EMF10116 & IPR000898 & PF01231 \\
\hline \multicolumn{7}{|c|}{ Hydrolase activity (GO:0016787) } \\
\hline CBET3_10362-RA & 5'/3'-nucleotidase SurE family & 2.12 & $2 \mathrm{E}-107$ & XP_001267521 & IPR002828 & PF01975 \\
\hline CBET3_09066-RA & Carbon-nitrogen hydrolase & 1.59 & $1 \mathrm{E}-135$ & EMF12014 & IPR003010 & PF00795 \\
\hline CBET3_11455-RA & Metallo-dependent hydrolase & -1.41 & $1 \mathrm{E}-100$ & EHA27811 & IPR006680 & PF01979 \\
\hline \multicolumn{7}{|c|}{ Integral component of membrane (GO:0016021) } \\
\hline CBET3_04709-RA & GPR1/FUN34/YaaH-class plasma membrane protein & 1.73 & $1 \mathrm{E}-157$ & KJX99469 & IPR000791 & PF01184 \\
\hline \multicolumn{7}{|c|}{ Lipid metabolic process (GO:0006629) } \\
\hline CBET3_07897-RA & $\alpha / \beta$ hydrolase & 3.68 & $2 \mathrm{E}-148$ & EMF14093 & IPR002921 & PF01764 \\
\hline \multicolumn{7}{|c|}{ Metabolic process (GO:0008152) } \\
\hline CBET3_02504-RA & $17-\beta$-hydroxysteroid dehydrogenase & 4.51 & $1 E-166$ & 3IS3_A & IPR002198 & PF00106 \\
\hline
\end{tabular}




$\begin{array}{ll}\text { CBET3_10899-RA } & \text { 2OG-Fe(II) oxygenase family oxidoreductase } \\ \text { CBET3_09080-RA } & \text { Aldehyde dehydrogenase } \\ \text { CBET3_10854-RA } & \alpha / \beta \text { hydrolase } \\ \text { CBET3_07866-RA } & \text { AMP-dependent synthetase/ligase } \\ \text { CBET3_05061-RA } & \text { Cutinase } \\ \text { CBET3_02220-RA } & \text { Di-copper centre-containing protein } \\ \text { CBET3_10853-RA } & \text { FAD/NAD(P)-binding domain-containing protein } \\ \text { CBET3_11210-RA } & \text { Fatty acid transporter } \\ \text { CBET3_02475-RA } & \text { Hypothetical protein } \\ \text { CBET3_02511-RA } & \text { Pentachlorophenol 4-monooxygenase } \\ \text { Oxidation-reduction process (GO:0055114) } \\ \text { CBET3_08056-RA } & \alpha \text {-ketoglutarate-dependent sulfonate dioxygenase } \\ \text { CBET3_11021-RA } & \text { Cellobiose dehydrogenase-like protein } \\ \text { CBET3_00516-RA } & \text { Cytochrome P450 } \\ \text { CBET3_08201-RA } & \text { Cytochrome P450 } \\ \text { CBET3_09476-RA } & \text { Cytochrome P450 } \\ \text { CBET3_11198-RA } & \text { Cytochrome P450 } \\ \text { CBET3_05704-RA } & \text { Cytochrome P450 } \\ \text { CBET3_07330-RA } & \text { Glucooligosaccharide oxidase } \\ \text { CBET3_01629-RA } & \text { Glucose-methanol-choline oxidoreductase } \\ \text { CBET3_04048-RA } & \text { Zinc-binding oxidoreductase } \\ \text { Phosphopantetheine binding (GO:0031177) } \\ \text { CBET3_02473-RA } & \text { Polyketide synthase } \\ \text { Protein binding (GO:0005515) } \\ \text { CBET3_04045-RA } & \text { Ankyrin repeat domain containing protein } \\ \text { CBET3_04067-RA } & \text { F-box and JmjC domain protein } \\ \text { CBET3_08202-RA } & \text { Glutathione s-transferase like protein } \\ \text { CBET3_08159-RA } & \text { Hypothetical protein } \\ \text { Protein phosphorylation (GO:0006468) } \\ \text { CBET3_05141-RA } & \text { Kinase-like protein } \\ \text { CBET3_03148-RA } & \text { Protein kinase } \\ \text { Proteolysis (GO:0006508) } & \end{array}$

\begin{tabular}{|c|c|c|c|c|}
\hline 1.68 & $4 \mathrm{E}-49$ & EKG22582 & IPR006620 & \\
\hline 1.51 & 0.0 & EMF11855 & IPR015590 & PF00171 \\
\hline-1.89 & $1 \mathrm{E}-129$ & EMF09451 & IPR013094 & PF07859 \\
\hline-1.40 & 0.0 & EKG13702 & IPR000873 & PF00501 \\
\hline 2.21 & $4 \mathrm{E}-59$ & XP_002556743 & IPR000675 & PF01083 \\
\hline 3.69 & $7 E-179$ & EMF10811 & IPR002227 & PF00264 \\
\hline-1.90 & $4 E-157$ & EMF09450 & IPR003042 & PF01494 \\
\hline 1.96 & 0.0 & EMF09843 & IPR000873 & PF00501 \\
\hline 3.27 & 0.0 & ESZ98968 & IPR003042 & \\
\hline 3.03 & 0.0 & XP_001821572 & IPR002938 & PF01494 \\
\hline-1.82 & $1 \mathrm{E}-147$ & CRG91408 & IPR003819 & PF02668 \\
\hline 1.86 & 0.0 & KJX95645 & IPR000172 & PF00732 \\
\hline 1.57 & 0.0 & EMF17880 & IPR001128 & PF00067 \\
\hline 1.57 & 0.0 & EMF13245 & IPR001128 & PF00067 \\
\hline 1.55 & 0.0 & EMF12016 & IPR001128 & PF00067 \\
\hline 1.52 & 0.0 & EMF10229 & IPR001128 & PF00067 \\
\hline 1.59 & 0.0 & EKG12102 & IPR002401 & PF00067 \\
\hline-1.49 & $1 \mathrm{E}-148$ & EMF09348 & IPR006094 & PF01565 \\
\hline-1.60 & 0.0 & EKG16305 & IPR012132 & PF00732 \\
\hline-1.43 & $1 \mathrm{E}-137$ & EMF10849 & IPR013149 & PF00107 \\
\hline 1.72 & 0.0 & XP_002482968 & IPR020806 & \\
\hline-2.29 & 0.0 & KJX95302 & IPR020683 & PF12796 \\
\hline-2.65 & 0.0 & KEQ82319 & IPR001810 & PF12937 \\
\hline 1.82 & $2 \mathrm{E}-175$ & KJX94096 & IPR004045 & PF13409 \\
\hline-1.47 & $1 E-53$ & KJX96133 & IPR000210 & PF00651 \\
\hline 1.42 & $9 \mathrm{E}-147$ & EMF07926 & IPR000719 & PF00069 \\
\hline 2.33 & $1 \mathrm{E}-101$ & XP_007924148 & IPR001245 & PF07714 \\
\hline
\end{tabular}




\begin{tabular}{|c|c|c|c|c|c|c|}
\hline CBET3_12252-RA & Carboxypeptidase S1 & 1.93 & 0.0 & EGE05173 & IPR001563 & PF00450 \\
\hline CBET3_08150-RA & Trypsin-like serine protease & 1.64 & $1 \mathrm{E}-57$ & XP_006961656 & IPR001254 & PF00089 \\
\hline \multicolumn{7}{|c|}{ Regulation of transcription, DNA-templated (GO:0006355) } \\
\hline CBET3_02344-RA & $\mathrm{Zn}(\mathrm{II})_{2} \mathrm{Cys}_{6}$ transcription factor (AfIR) & 3.28 & $1 \mathrm{E}-24$ & KKA18106 & IPR002409 & PF08493 \\
\hline \multicolumn{7}{|c|}{ Response to stress (GO:0006950) } \\
\hline CBET3_11653-RA & RTA1 domain protein & 8.00 & $2 \mathrm{E}-117$ & KJX94617 & IPR007568 & PF04479 \\
\hline \multicolumn{7}{|c|}{ Steroid biosynthetic process (GO:0006694) } \\
\hline CBET3_00902-RA & C-3 sterol dehydrogenase (Erg26) & 1.47 & 0.0 & EMF17180 & IPR002225 & PF01073 \\
\hline \multicolumn{7}{|c|}{ Transmembrane transport (GO:0055085) } \\
\hline CBET3_02206-RA & Hexose transporter & -2.20 & 0.0 & ACR78273 & IPR003663 & PF00083 \\
\hline CBET3_08810-RA & Histidine permease & -1.77 & 0.0 & EMF13360 & IPR004841 & PF00324 \\
\hline CBET3_06018-RA & Major facilitator superfamily transporter & 2.44 & $6 \mathrm{E}-138$ & XP_007274312 & IPR011701 & PF07690 \\
\hline CBET3_01824-RA & Major facilitator superfamily transporter & 2.26 & 0.0 & XP_003065775 & IPR011701 & PF07690 \\
\hline CBET3_03348-RA & Major facilitator superfamily transporter & 1.34 & $1 \mathrm{E}-167$ & EME48032 & IPR011701 & PF07690 \\
\hline CBET3_10856-RA & Major facilitator superfamily general substrate transporter & -3.13 & 0.0 & EMF09454 & IPR011701 & PF07690 \\
\hline CBET3_11268-RA & Major facilitator superfamily general substrate transporter & 1.54 & 0.0 & EMF09835 & IPR011701 & PF07690 \\
\hline CBET3_04140-RA & Peptide transporter & -1.72 & 0.0 & ENH84505 & IPR004813 & PF03169 \\
\hline \multicolumn{7}{|c|}{ Transport (GO:0006810) } \\
\hline CBET3_05001-RA & $A B C$ transporter & 5.52 & 0.0 & EMF08365 & IPR003439 & PF00005 \\
\hline CBET3_03349-RA & $A B C$ transporter, $A B C-A$ family & 1.48 & 0.0 & XP_007924170 & IPR026082 & PF00005 \\
\hline \multicolumn{7}{|c|}{ Ubiquitin-dependent protein catabolic process (GO:0006511) } \\
\hline CBET3_10720-RA & Cullin repeat-containing protein & -1.87 & $2 \mathrm{E}-32$ & KEQ88354 & IPR001373 & PF00888 \\
\hline \multicolumn{7}{|l|}{ Unclassified } \\
\hline CBET3_05042-RA & Acetyltransferase-like protein & -2.32 & $4 \mathrm{E}-90$ & KJX94255 & IPR016181 & \\
\hline CBET3_06118-RA & Autophagy protein & -1.40 & 0.0 & EMF11171 & IPR024671 & PF11700 \\
\hline CBET3_07833-RA & Beta lactamase-like protein & -3.16 & $0 \mathrm{E}+00$ & EME48565 & IPR001466 & PF00144 \\
\hline CBET3_11652-RA & C6 zinc finger domain-containing protein & 3.33 & $3 \mathrm{E}-28$ & KJX94621 & & \\
\hline CBET3_11585-RA & Carbohydrate esterase family 3 protein & 4.93 & $2 \mathrm{E}-99$ & EMF10206 & IPR013830 & PF13472 \\
\hline CBET3_11060-RA & Fasciclin domain-containing protein & 1.89 & $3 \mathrm{E}-48$ & XP_007295171 & IPR000782 & PF02469 \\
\hline CBET3_00365-RA & Glycosyl transferase & -2.53 & $9 \mathrm{E}-83$ & EKV16648 & IPR029044 & \\
\hline CBET3_05558-RA & Hypothetical protein & 4.83 & $8 \mathrm{E}-159$ & EMF08800 & & \\
\hline CBET3_00511-RA & hypothetical protein & 2.97 & $9 \mathrm{E}-93$ & EME49690 & & \\
\hline
\end{tabular}




\author{
CBET3_10668-RA \\ CBET3_05254-RA \\ CBET3_03147-RA \\ CBET3_02508-RA \\ CBET3_06857-RA \\ CBET3_01561-RA \\ CBET3_08337-RA \\ CBET3_09241-RA \\ CBET3_01612-RA \\ CBET3_06982-RA \\ CBET3_02518-RA \\ CBET3_02546-RA \\ CBET3_09459-RA \\ CBET3_11415-RA \\ CBET3_11454-RA \\ CBET3_11257-RA \\ CBET3_12197-RA \\ CBET3_01494-RA \\ CBET3_08277-RA \\ CBET3_02870-RA \\ CBET3_05929-RA \\ CBET3_10955-RA \\ CBET3_05246-RA \\ CBET3_05560-RA \\ CBET3_10855-RA \\ CBET3_05304-RA \\ CBET3_03830-RA \\ CBET3_00215-RA \\ CBET3_03842-RA \\ CBET3 00212-RA \\ CBET3 05545-RA \\ CBET3_04143-RA
}

Hypothetical protein

Hypothetical protein

Hypothetical protein

Hypothetical protein

Hypothetical protein

Hypothetical protein

Hypothetical protein

Hypothetical protein

Hypothetical protein

Hypothetical protein

Hypothetical protein

Hypothetical protein

Hypothetical protein

Hypothetical protein

Hypothetical protein

Hypothetical protein

Hypothetical protein

Hypothetical protein

Hypothetical protein

Hypothetical protein

Hypothetical protein

Hypothetical protein

Hypothetical protein

Hypothetical protein

Hypothetical protein

Hypothetical protein

Hypothetical protein

Hypothetical protein with HET domain

Hypothetical protein with tetratricopeptide repeat domain

Major facilitator superfamily, general substrate transporter

NPP1 domain-containing protein

P-loop containing nucleoside triphosphate hydrolase

$\begin{array}{ccccc}2.73 & \text { 1E-98 } & \text { XP_007928244 } & & \\ 2.27 & 0.0 & \text { EMF08527 } & & \\ 2.15 & 8 E-18 & \text { EMR84685 } & & \\ 2.10 & 1 E-166 & \text { XP_007696463 } & \text { IPR025337 } & \text { PF14027 } \\ 1.91 & 5 E-115 & \text { XP_007930785 } & & \\ 1.79 & 3 E-22 & \text { XP_001932896 } & \text { IPR011050 } & \\ 1.77 & 1 E-80 & \text { EMF13537 } & & \\ 1.72 & 3 E-90 & \text { KJX99495 } & \text { IPR010730 } & \text { PF06985 } \\ 1.79 & 5 E-11 & \text { EMF16235 } & & \\ 2.60 & 1 E-94 & \text { EME39020 } & & \\ -1.42 & 3 E-138 & \text { EMF16076 } & \text { IPR025187 } & \text { PF13430 } \\ -1.53 & 2 E-15 & \text { XP_007923133 } & & \\ -1.58 & 0.0 & \text { KJX99536 } & \text { IPR021840 } & \text { PF11915 } \\ -1.60 & 0.0 & \text { BAN91486 } & & \\ -1.61 & 0.0 & \text { EMF09894 } & \text { IPR009571 } & \text { PF06687 } \\ -1.65 & 5 E-75 & \text { EMF10176 } & \text { IPR018392 } & \text { PF01476 } \\ -1.76 & 3 E-104 & \text { EQL33191 } & & \\ -1.82 & 1 E-33 & \text { EWG50720 } & & \\ -1.80 & 4 E-75 & \text { EMF10352 } & & \\ -1.84 & 3 E-66 & \text { EMF15383 } & & \\ -2.14 & 6 E-13 & \text { EME46074 } & & \\ -2.13 & 4 E-179 & \text { EMF09808 } & & \\ -2.23 & 2 E-21 & \text { XP_007777459 } & & \\ -2.22 & 2 E-130 & \text { EMF08810 } & & \\ -1.76 & 1 E-14 & \text { EMF09452 } & & \\ -2.45 & 6 E-151 & \text { EME38618 } & & \\ -3.29 & 1 E-104 & \text { XP_003857461 } & \text { IPR007310 } & \text { PF04183 } \\ 1.29 & 9 E-29 & \text { EWZ48880 } & \text { IPR010730 } & \text { PF06985 } \\ 2.99 & 1 E-104 & \text { XP_002118036 } & \text { IPR001440 } & \text { PF00515 } \\ 4.31 & 2 E-117 & \text { KG053278 } & \text { IPR020846 } & \\ 1.64 & 8 E-120 & \text { XP_007588068 } & \text { IPR008701 } & \text { PF05630 } \\ 1.58 & 4 E-145 & \text { EMF10878 } & \text { IPR027417 } & \text { PF09439 }\end{array}$




\begin{tabular}{|c|c|c|c|c|c|c|}
\hline CBET3_00211-RA & Siderophore esterase IroE-like & 4.76 & $2 \mathrm{E}-125$ & XP_001276792 & IPR000801 & PF00756 \\
\hline CBET3_03652-RA & ThiJ/Pfpl family protein & -1.85 & $5 E-37$ & KFG86071 & IPR025628 & PF13278 \\
\hline CBET3_02345-RA & Toxin biosynthesis regulatory protein & 2.75 & $2 \mathrm{E}-65$ & CBF90109 & IPR011991 & \\
\hline CBET3_11414-RA & Zn-dependent hydrolase & -2.17 & $4 \mathrm{E}-155$ & ENH83839 & IPR001279 & PF00753 \\
\hline \multicolumn{7}{|c|}{ No annotation available } \\
\hline CBET3_05717-RA & No significant similarity & 1.34 & & & & \\
\hline CBET3_02219-RA & No significant similarity & 2.53 & & & & \\
\hline CBET3_02217-RA & No significant similarity & 2.40 & & & & \\
\hline CBET3_09434-RA & No significant similarity & -1.82 & & & & \\
\hline CBET3_03832-RA & No significant similarity & -2.26 & & & & \\
\hline CBET3_10751-RA & No significant similarity & -2.27 & & & & \\
\hline CBET3_02070-RA & No significant similarity & -2.27 & & & & \\
\hline CBET3_10954-RA & No significant similarity & -3.19 & & & & \\
\hline
\end{tabular}

*Biological process $\mathrm{GO}$ term ontology was given preference when grouping genes. If no Biological Process GO term was identified for a gene,

Molecular function and Cellular component GO terms were used for classification.

${ }^{1}$ Genes were considered differentially expressed if Q-values $\leq 0.001$ and $\log _{2}$ fold regulation differences $\geq 1.0$ using $t$-tests of expression values between mock- and tetraconazole-treatments. 
Table 3. $\mathrm{EC}_{50}$ analyses of Cercospora beticola strains containing ectopic or site-directed mutations in candidate DMI-resistance genes.

\begin{tabular}{|c|c|c|c|}
\hline \multirow[b]{2}{*}{ Gene } & \multirow[b]{2}{*}{ Predicted function } & \multicolumn{2}{|c|}{ Average $\mathrm{EC}_{50}$ value $\left(\mu \mathrm{g} \mathrm{ml}^{-1}\right)^{*}$} \\
\hline & & Ectopic & Site-directed \\
\hline CBET3_11380-RA & 4-Carboxymuconolactone decarboxylase & $52.2( \pm 13.7)$ & $57.8( \pm 9.1)$ \\
\hline CBET3_11653-RA & RTA1 domain protein & $48.7( \pm 7.1)$ & $52.5( \pm 10.5)$ \\
\hline CBET3_11585-RA & Carbohydrate esterase family 3 protein & $56.1( \pm 3.1)$ & $60.2( \pm 16.4)$ \\
\hline CBET3_11652-RA & C6 zinc finger domain-containing protein & $53.4( \pm 5.7)$ & $51.0( \pm 6.1)$ \\
\hline CBET3_02344-RA & C6 transcription factor (Af|R) & $51.9( \pm 8.4)$ & $55.9( \pm 10.5)$ \\
\hline
\end{tabular}

*The $\mathrm{EC}_{50}$ value of the progenitor strain 10-73-4 was $35.9( \pm 2.6) \mu \mathrm{g} \mathrm{ml}^{-1}$. Values in parenthesis indicate standard deviation of the mean of three individual mutants.

Table 4. Primers used in this study.

\begin{tabular}{lll}
\hline Primer name & Specificity/role* & \multicolumn{1}{c}{ Sequence (5' to 3') } \\
\hline MDB-277 & Split-marker HYG-F & GACGTTGTAAAACGACGGCCAGTG \\
MDB-258 & Split-marker HY-R & GGATGCCTCCGCTCGAAGTA \\
MDB-259 & Split-marker YG-F & CGTTGCAAGACCTGCCTGAA \\
MDB-278 & Split-marker HYG-R & CACAGGAAACAGCTATGACCATGA \\
MDB-1145 & HYG R2 & GGCAGGTAGATGACGACCAT \\
MDB-1317 & CBET3_11653-RA 1F & TCTGAACCCTCAACGAGTCC \\
MDB-1318 & CBET3_11653-RA 2R & CACTGGCCGTCGTTTTACAACGTCGTTGCCGACACTTCTGTACA \\
MDB-1319 & CBET3_11653-RA 3F & TCATGGTCATAGCTGTTTCCTGTGTTCCCGTCTCCAATGCTTCT \\
MDB-1320 & CBET3_11653-RA 4R & GTCTCTCCGCTTGCCAATC \\
MDB-1429 & CBET3_11653-RA 5F & AGTGCCTGGTCCTTGATCAA \\
MDB-1396 & CBET3_11653-RA 6R & AACGGAAAAGCATGCAAGGT \\
MDB-1325 & CBET3_11585-RA 1F & GGCGTTTTCTGGCATACGAA \\
MDB-1326 & CBET3_11585-RA 2R & CACTGGCCGTCGTTTTACAACGTCCCGCCATGACTTGATTCGTT \\
MDB-1327 & CBET3_11585-RA 3F & TCATGGTCATAGCTGTTTCCTGTGAGGCTACCGAGGAGATGGTA \\
MDB-1328 & CBET3_11585-RA 4R & CCTGGCAGATGTCTCCTCAA
\end{tabular}




$\begin{array}{ll}\text { MDB-1431 } & \text { CBET3_11585-RA 5F } \\ \text { MDB-1398 } & \text { CBET3_11585-RA 6R } \\ \text { MDB-1333 } & \text { CBET3_11652-RA 1F } \\ \text { MDB-1334 } & \text { CBET3_11652-RA 2R } \\ \text { MDB-1335 } & \text { CBET3_11652-RA 3F } \\ \text { MDB-1336 } & \text { CBET3_11652-RA 4R } \\ \text { MDB-1433 } & \text { CBET3_11652-RA 5F } \\ \text { MDB-1400 } & \text { CBET3_11652-RA 6R } \\ \text { MDB-1337 } & \text { CBET3_02344-RA 1F } \\ \text { MDB-1338 } & \text { CBET3_02344-RA 2R } \\ \text { MDB-1339 } & \text { CBET3_02344-RA 3F } \\ \text { MDB-1340 } & \text { CBET3_02344-RA 4R } \\ \text { MDB-1434 } & \text { CBET3_02344-RA 5F } \\ \text { MDB-1401 } & \text { CBET3_02344-RA 6R } \\ \text { MDB-1297 } & \text { CBET3_11380-RA 1F } \\ \text { MDB-1298 } & \text { CBET3_11380-RA 2R } \\ \text { MDB-1299 } & \text { CBET3_11380-RA 3F } \\ \text { MDB-1300 } & \text { CBET3_11380-RA 4R } \\ \text { MDB-1422 } & \text { CBET3_11380-RA 5F } \\ \text { MDB-1391 } & \text { CBET3_11380-RA 6R }\end{array}$

\section{MDB-143}

MDB-1334

MDB-1335

MDB-1400

MDB-1337

MDB-1340

MDB-1297

MDB-1298

MDB-1391
CAATCAACAGATCAGCGCGA

GTCTCCGTGTTTCAGCGATC

CTGTGTAGGCCTCGACTTTC

CACTGGCCGTCGTTTTACAACGTCCCGGGCTGATAAGGTGGAAT

TCATGGTCATAGCTGTTTCCTGTGAGAAGTTGTACACCTGGGCA

CAGCACCCTCGCATTCTTC

ATCACAGGAAGAACGGCTCA

TTCACCGTAGCCCAAGTGAT

CTTCTCGAACATTGGGCCAC

CACTGGCCGTCGTTTTACAACGTCTCTTGGTAATTGGAGGCGGT

TCATGGTCATAGCTGTTTCCTGTGCACGCGCTATCATTCAGTCG

TACTTCCGACACGAAGCCAT

AACCTCTTCTCGGGACACTG

CCGCTAAGAATGCTGTCACC

ACAGGAGGAAGAAGGTGGTG

CACTGGCCGTCGTTTTACAACGTCCTTACCATCATCGGCTGTGC

TCATGGTCATAGCTGTTTCCTGTGCAGCTTTCCAGGACCACAAC

GCAAAGAGAGTGATAGCCGC

GAACTTGTACGGGTCGATGC

CAGTCCACTCATACGTTGCG

*Primer nomenclature and design essentially as described by Goswami (2012). 


\section{FIGURE LEGENDS}

Figure 1. Overlap of genes identified as differentially-expressed ( $Q$-value $\leq 0.001$, and $\log _{2}$ fold regulation differences $\geq 1.0$ ) between mock- and tetraconazole-treatments for each Cercospora beticola strain. $C$. beticola strain 09-32 is DMI-sensitive and 10-73-4 is DMI-resistant.

Figure 2. Ergosterol pathway in Cercospora beticola. A. DMI-exposure in both strains causes an induction (red) of ergosterol pathway genes. B. Fragments per kilobase of transcript per million (FPKM) reads for each gene identified as differentially-expressed in the ergosterol pathway in both C. beticola strains. C. beticola strain 09-32 is DMI-sensitive and 10-73-4 is DMI-resistant. Values represent the average FPKM values of two biological replicates. Error bars are standard deviations obtained via CummeRbund. 


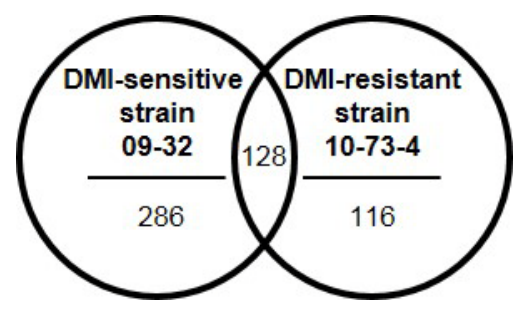

Figure 1. 
A
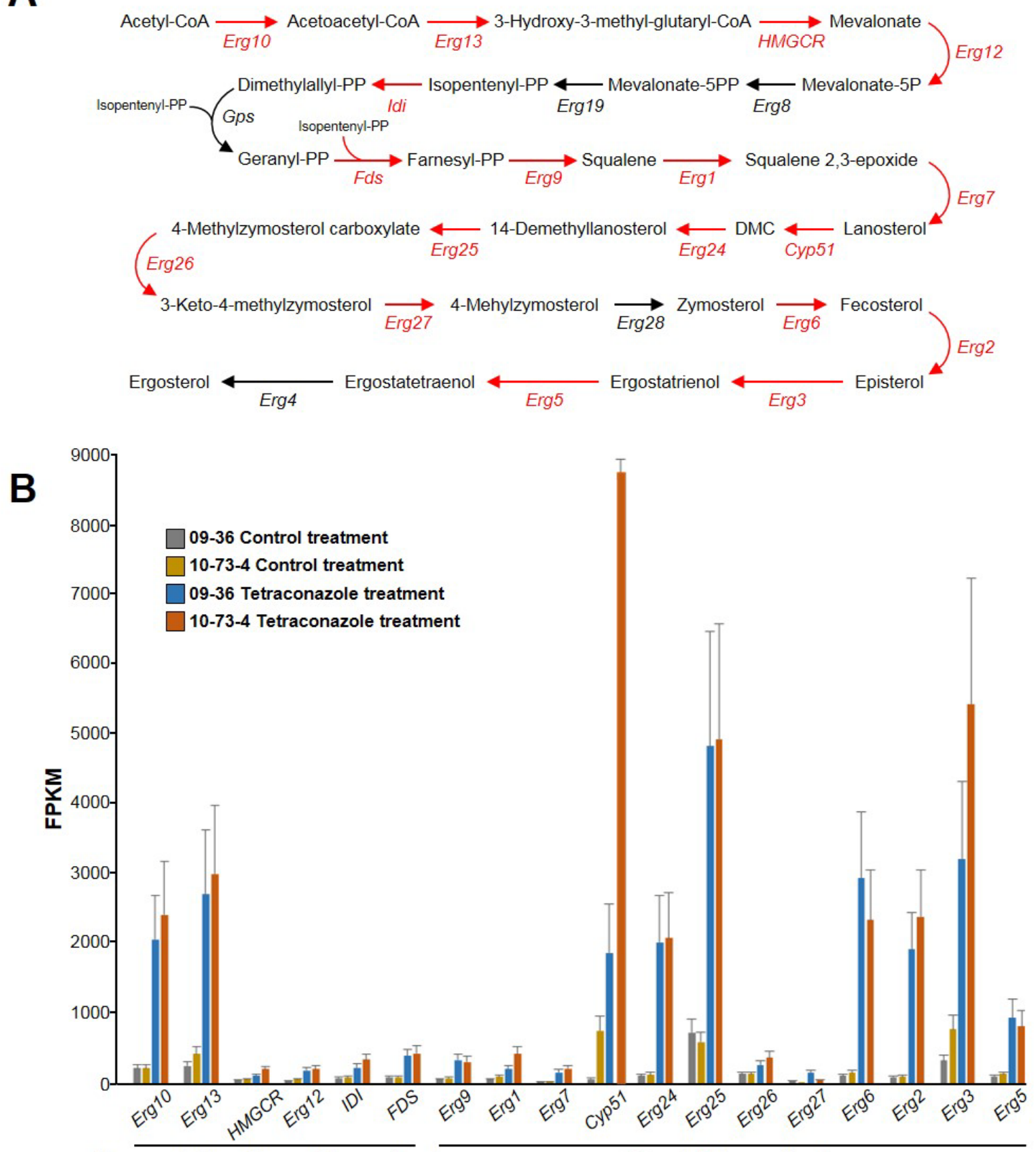

Terpenoid backbone biosynthesis

Steroid biosynthesis

Figure 2. 